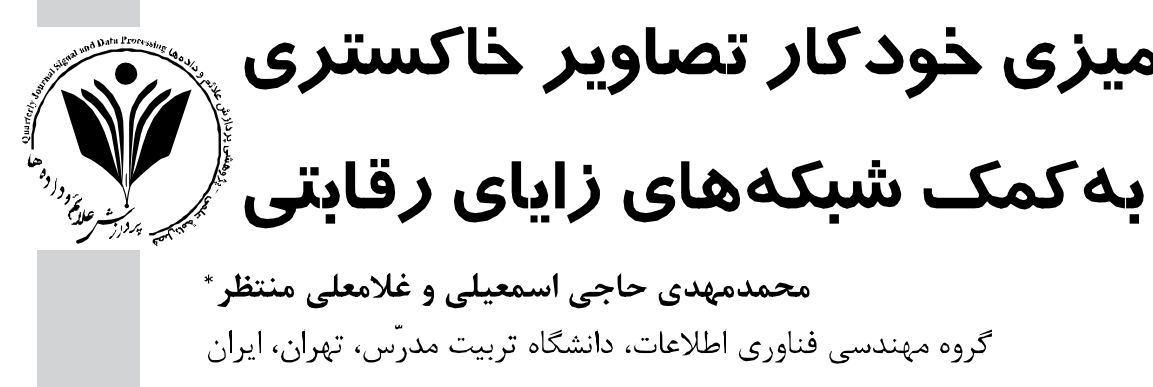

جكيله

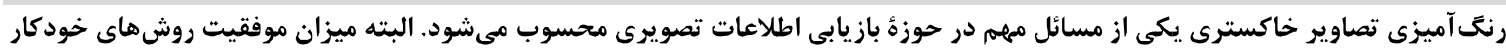

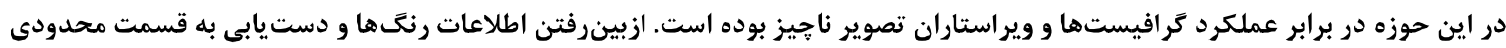

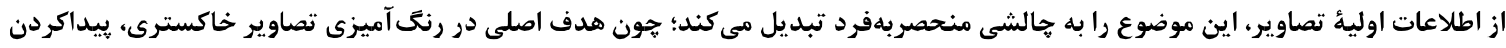

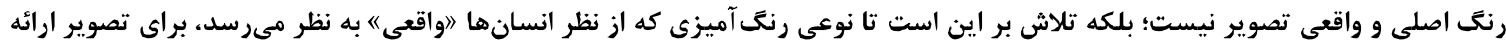

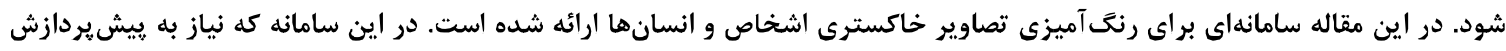

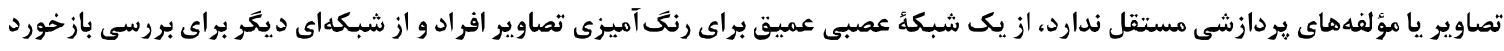

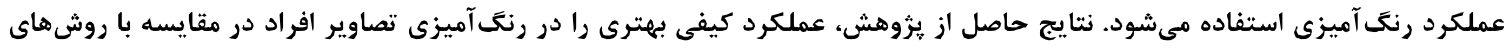

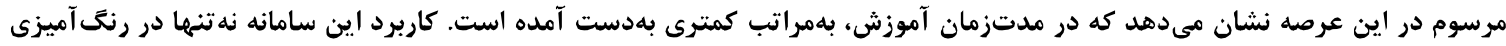

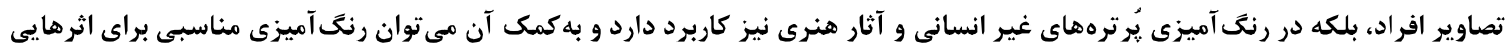

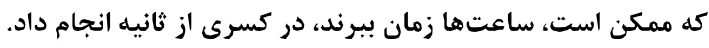
وازرَان كليدى: رنكَآميزى، تصاوير خاكسترى، شبكهاى عصبى عميق، شبكههاى زاياى رقابتى، بازيابى اطلاعات تصويرى

\title{
Automatic Colorization of Grayscale Images Using Generative Adversarial Networks
}

Mohammad Mahdi Haji-Esmaeili \& Gholam Ali Montazer*

Information Technology Engineering, Tarbiat Modares University, Tehran, Iran

\begin{abstract}
Automatic colorization of gray scale images poses a unique challenge in Information Retrieval. The goal of this field is to colorize images which have lost some color channels (such as the RGB channels or the AB channels in the LAB color space) while only having the brightness channel available, which is usually the case in a vast array of old photos and portraits. Having the ability to colorize such images would give us a multitude of possibilities ranging from colorizing old and historic images to providing alternate colorizations for real images or artistic creations. Be that as it may, the progress in this field is trivial compared to what the professionals are able to do using special-purpose applications such as Photoshop or GIMP. On the other hand, losing the information stored in color channels and having only access to the primary brightness channel, makes this problem a unique challenge, since the main aim of automatic colorization is not to find the image's "real" color but to colorize it in such a way that makes it "seem real" as the original color information is lost forever and the only way to colorize it, is to provide a somewhat "proper" estimation. In this research we propose a model to automatically colorize gray human portraits. We start by reviewing the methods used for the task of image colorization and provide an explanation as to why most of them collapse to a situation known as "Averaging". To counteract this effect, we design our end-to-end model with two
\end{abstract}

* Corresponding author * نويسنده عهدهدار مكاتبات 
separate deep neural networks forming a Generative Adversarial Network (GAN), one to colorize the images and the other to evaluate the colorization of the first network and guide it towards the proper distribution. The results show improvements over other proposed methods in this field especially in the case of colorizing human portraits along faster train times. This method not only works on real human portraits but also on non-human and artistic portraits that can be leveraged to colorize hand-drawn images some of which may take minutes up to hours by hand.

Keywords: colorization, gray scale images, deep neural networks, generative adversarial networks, image information retrieval

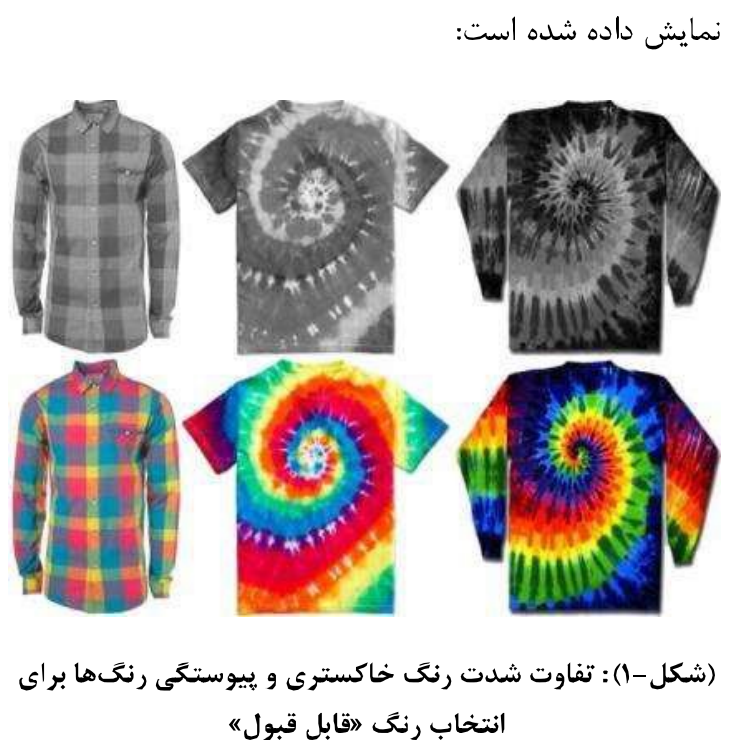

(Figure-1): The difference between grayscale intensity and color diversity for choosing the "proper color"

در تصاوير شكل (1)، تفاوت شدت روشنايى موجب بلوجودآمدن جايخشتهاى مختلفى براى رنخهاى قابل نقبول

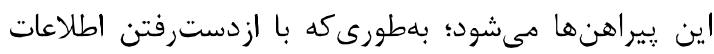

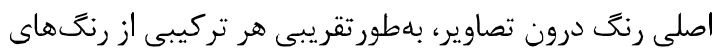

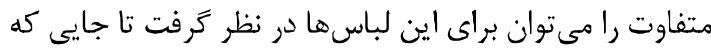
حتى در نقاطى كه يِيوستخى رنگى يكسان است، هىتوان از

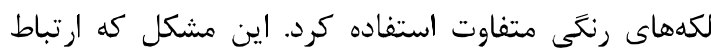

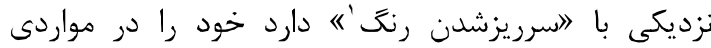

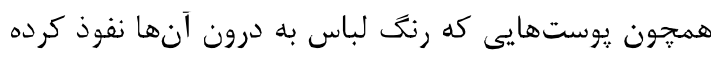

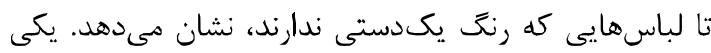

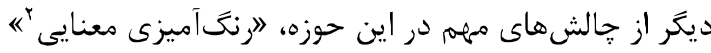
اشياى موجود در تصوير است كه بحث اصلى آن رنغَآميزى بر اساس مفاهيم معنايى است كه بهطورتقريبى هميشه براى

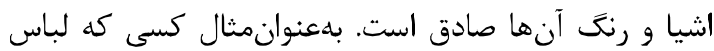

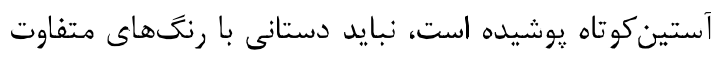

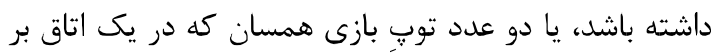

${ }^{1}$ Color Bleeding

${ }^{2}$ Semantic Colorization

\section{ه مقد}

در حال حاضر با حجم عظيمى از تصاوير قديمى و سياه و

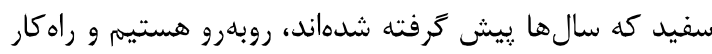

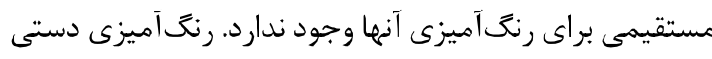

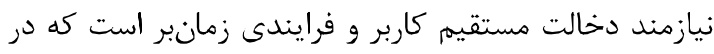
مواردى همجِون بررسى تصاوير همسان (براى انتخاب رنگ)،

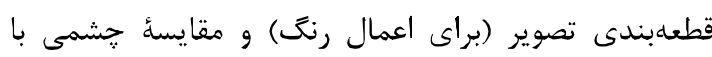

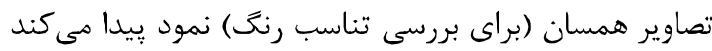
[1] يا Arkvis Coloriage Photoshop تخصص در كاربرد ابزارهاى يادشده دارد. هماكنون گروههاى مباحثه و شبكههاى اجتماعى متعددى شكل گرفتهاند كه از

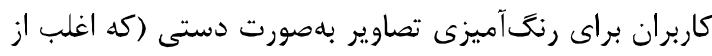

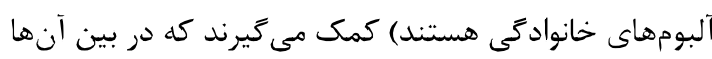

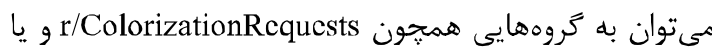
r/Colorization مسأله اصلى در اين يثوهش، رنتىآميزى قابل قبول

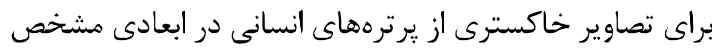

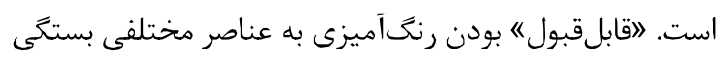

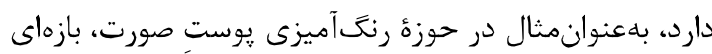

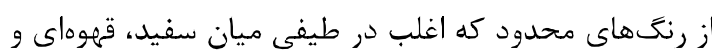

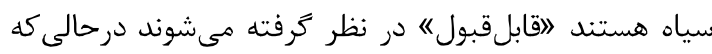

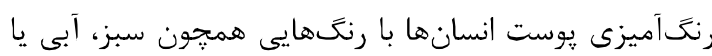
فسفرى بههيجوجه قابلقبول محسوب نمىشود [3]. از طرفى نس

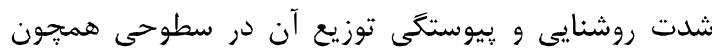

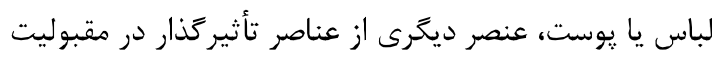

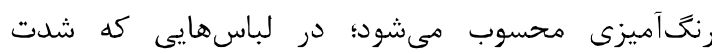

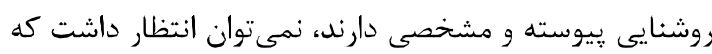
قسمتى از لباس به رنت آبى و قطعات و تكههايى از آن قرمز دانئه باشد و حتى اءر سايهاى بر روى لباس افتاده و ميزان روشنايى إنى

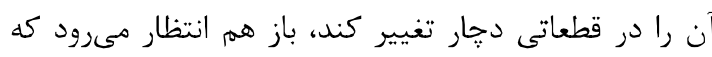
رنگ اصلى لباس در اين قطعات فقط با شدتى متفاوت حضور

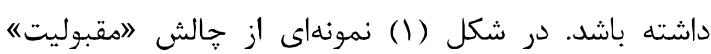


ميانگينى از تصاوير يوست اغلب منجر به رنت سوبيايى مىشود كه در ستون سمت راست شكل (r) ديده مى رئود. اين موضوع در مورد رنخ قرمز لبهاى افراد نيز صادق است

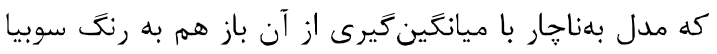
براى لبها مىرسد. اين جالث نهتنها در رنت آميزى صورتها

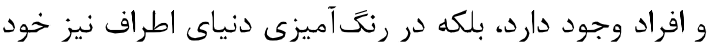

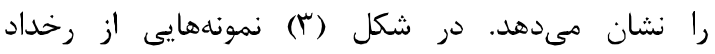
ميانَينگيرى در رنغَآميزى تصاويرى با دامنههاى متفاوت نمايش داده شده است.

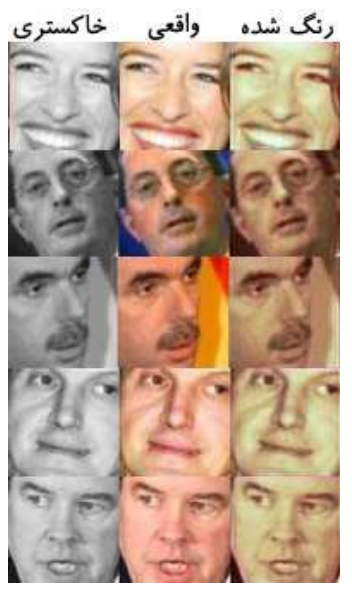

(شكل-T) : تأثير تابع هدف MSE بر رنغَآميزى صورت (Figure-2): The effect of MSE on colorizing portraits [5]

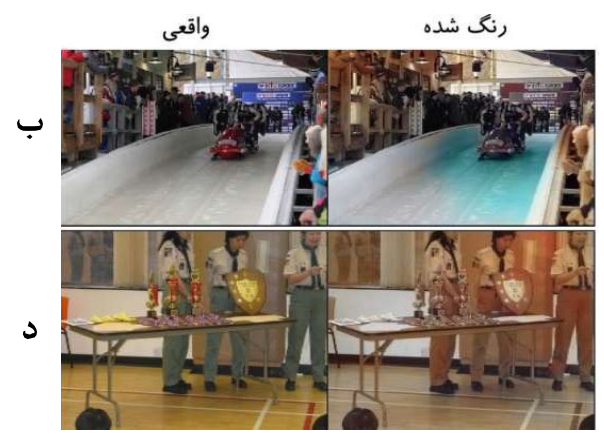
الف

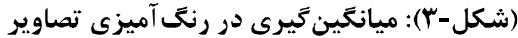

(Figure-3): Averaging problem in image colorization [6]

در تصوير (الف) قسمت اعظمى از تصوير يا رنغَآميزى نشده و يا داراى رنت سوبيا است و از طرفى رنكَآميزى ماشين

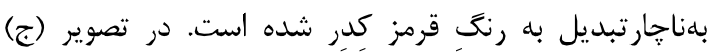

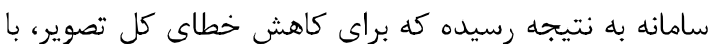
ميانگينگيرى به خطاى كمترى مىرسد تا اينكه بخواهد اشياى درون تصوير را بلهورتى جداكانه رنتآميزى كند كهئ

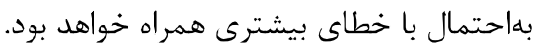

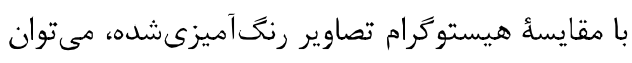
به تأثير ميانكين كيرى بر روى فضاى رنت تصاوير يى برد. در
روى زمين افتادهاند، نبايد ساختار رنگى متفاوتى داشته باشند؛

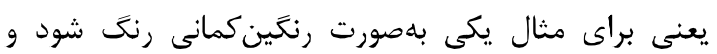

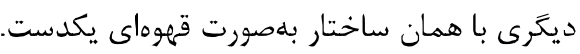
عموم روشهايى كه براى حل اين مسأله استفاده

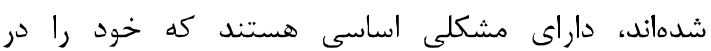
رنغآميزى تصاوير با رنگهاى مُرده و اغلب به رنتى سوبيا'

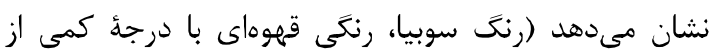
قرمزى است كه بهدليل فعل و انفعالات شيميايى، بخش اعظمى از تصاويرِشكارشده با دوربينهاى قديمى در طول زمان

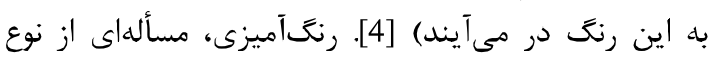
رگرسيون است و اغلب روش هاى به كارگرفتهشده در آن از تابع هدفى همجون ميانكين مربع خطا (MSE) بَ استفاده مى كنيند. با توجه به اينكه هدف نهايیى در اين مسأله، رنتىآميزى تصوير خاكسترى، بلنحوى است كه بيشترين شباهت را با با تصوير

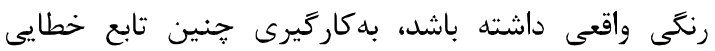
مناسب به نظر مىرسد. البته اين انتخاب، عملكرد بهينهسازى بلهي را بلصورت مستقيم تحت تأثير قرار مى دهد و سامانه را به سمتى سوق مىدهد تا با انتخاب رنخهايى مناسب براى كل

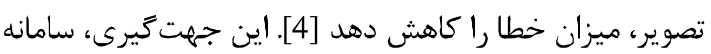
را وادار بـ انتخاب رنتهاى ميانهاى براى بسيارى از اشياى درون تصوير مى كند. بلعنوان نمونهاى مناسب از اين عملكرد

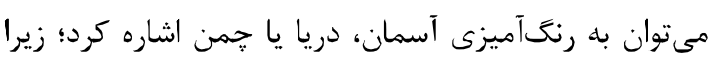
اين موارد در بيشتر حالات داراى رنخ هاى يكسانى هستند،

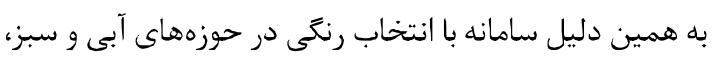
آنها را رنغىآميزى خواهد كرد. باوجود عملكرد مثبت سامانه در رنتَآميزى مفاهيمى با رنت ثابت، اين موضوع تأثيرى

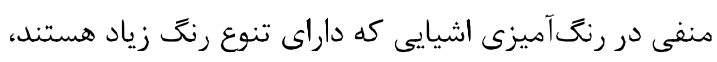
دارد. بهعنوانمثال، ساهانه با ديدن يك ماشين در تصوير،

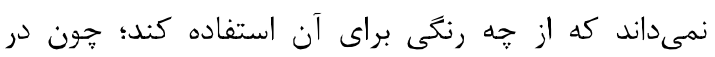
تصاويرى متعدد ماشينهايى با رنت قرمز، نارنجى، سرمهاى،

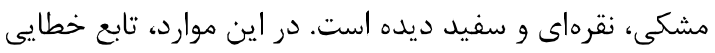

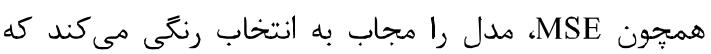
ميانغينى از رنتهايى است كه براى ماشين ديده است. اين مان

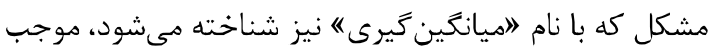

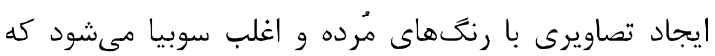
ناشى از ميانگين گيرى بيشتر رنتهايى است كه مدل از اشيا ديده است. در شكل (r) تعدادى از اين رنخَآميزىها نمايش

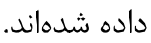

\footnotetext{
${ }^{1}$ Sepia

${ }^{2}$ Mean Squared Error
} 
جعلى هستند. دامنهُ عملكرد يك شبكة زاياى رقابتى مىتواند

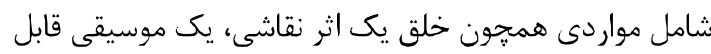

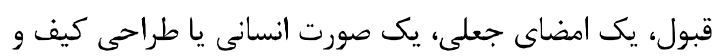

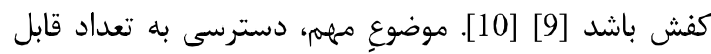
قبولى از دادههاى موجود در اين دامنه است. يس از انتخاب يك دامنهُ مشخص (براى مثال تصاويرِ

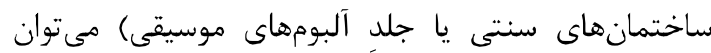

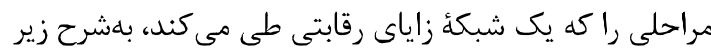
خلاصه كرد [9]: ا. مؤلفة زايا، يكى عدد تصادفى را بالعنوان ورودى انتخاب كرده و بر اساس آن يك خروجى جعلى (تصوير) ايجاد مى كند. r. خروجى جعلي مؤلفهُ زايا به همراه تصويرى واقعى از دامنه مورد نظر تحويل مؤلفه تمايزى مى جودي. r. مؤلفأ تمايزى، تصاوير جعلى و واقعى راكر موفته و دور در انتها

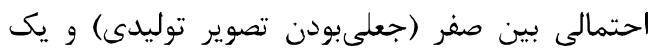

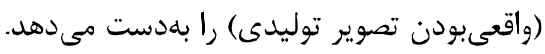

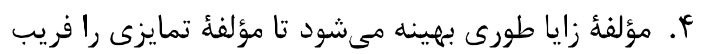
دهد (خروجى مؤلفهُ تمايزى را به سمت يك هدايت كند)

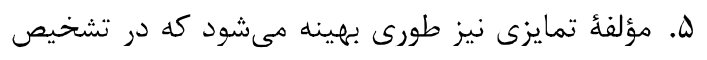

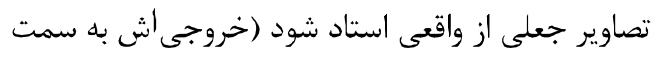

$$
\text { صفر هدايت شود) }
$$

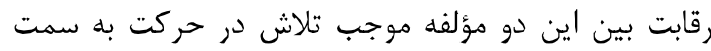

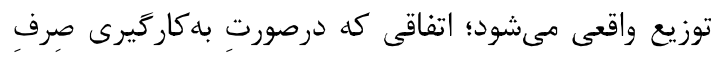

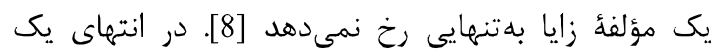

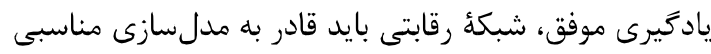

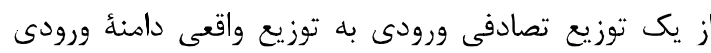

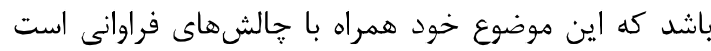

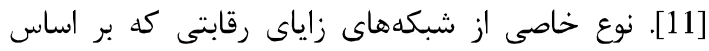

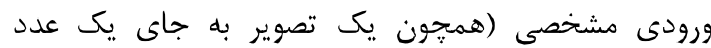

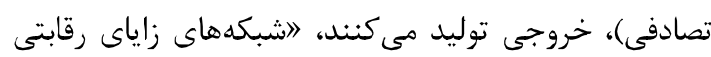

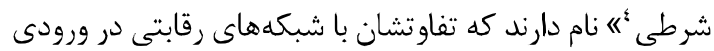

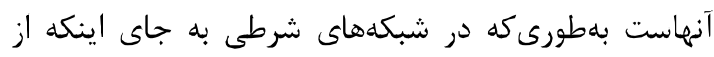

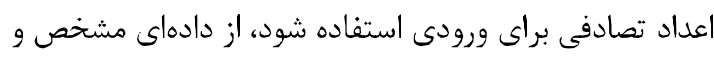
از دامنهاى مشخص استفاده مى شود (همجرون يك تصوير يا

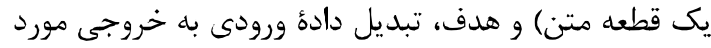

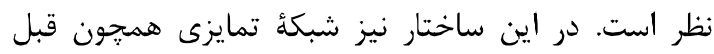

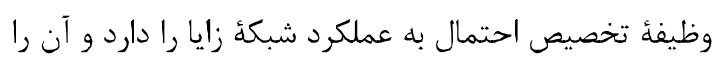

${ }^{4}$ Conditional GANs

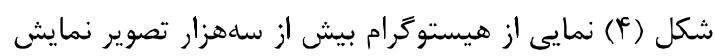

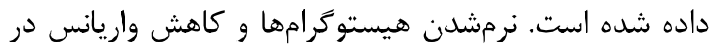

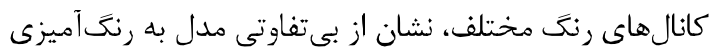

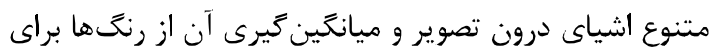
كاهش ميزان خطاى كل است.
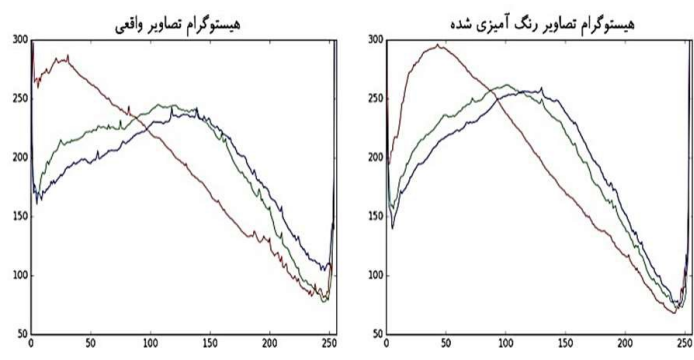

(شكل - (†): هيستو

(Figure-4): Color image histograms of faces and bodies

با توجه به نكات بالا، اين مقاله شامل بخشهاى زير

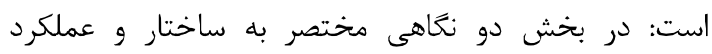

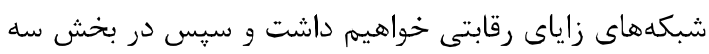

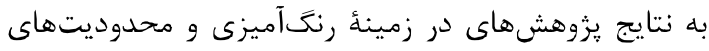

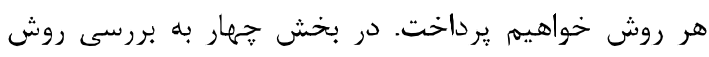

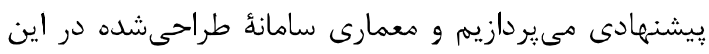

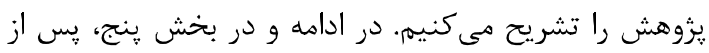

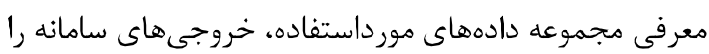

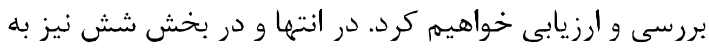

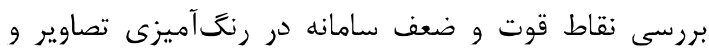

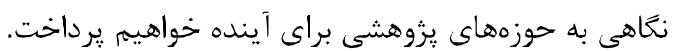

\section{r- شبكه هاى زاياى رقابتى (GAN')}

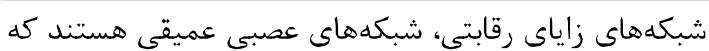
از دو شبكة دجزا و رقيب تشكيل شدهاند. اين شبكهها كه

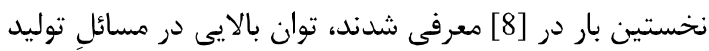

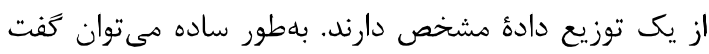

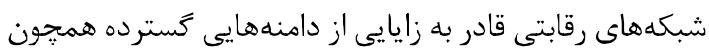

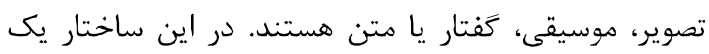

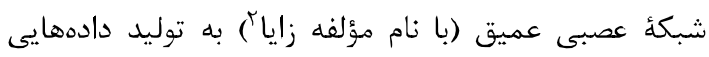

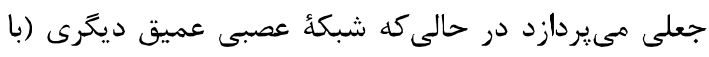

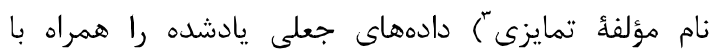

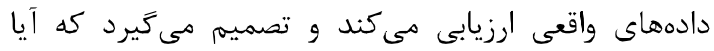

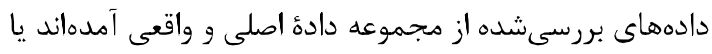

\footnotetext{
${ }^{1}$ Gencrative Adversarial Networks

${ }^{2}$ Generator

${ }^{3}$ Discriminator
} 
با استخراج اطلاعات از تصوير رنتى و تلفيق آن با تصوير

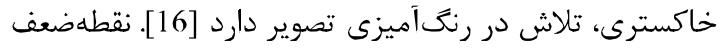

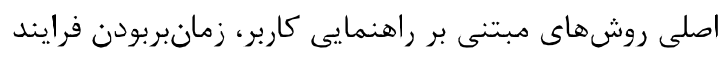

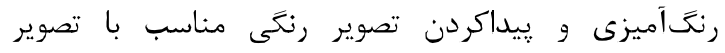

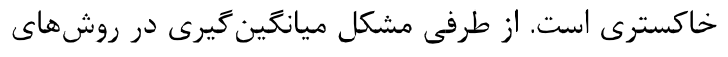

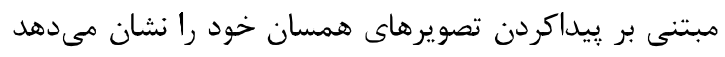

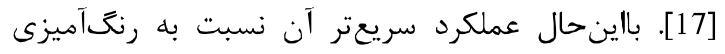

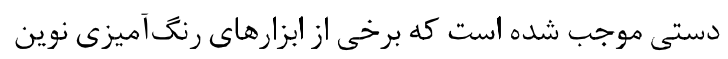

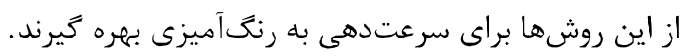

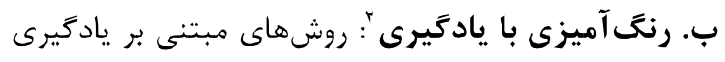

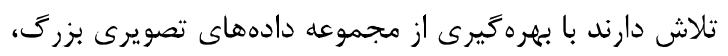

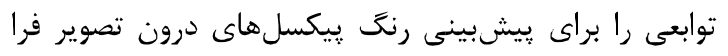

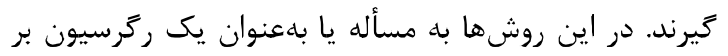

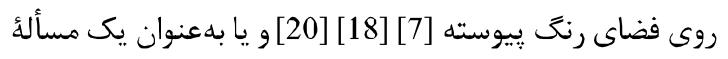

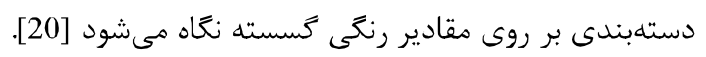

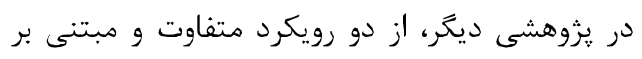

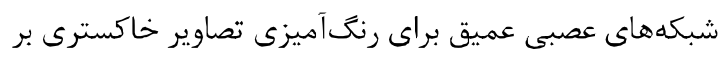

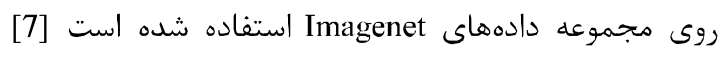

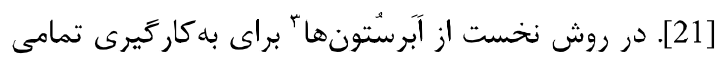

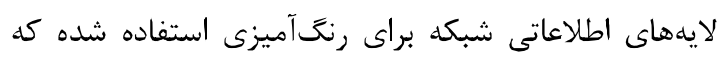

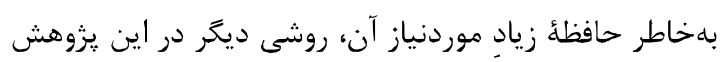

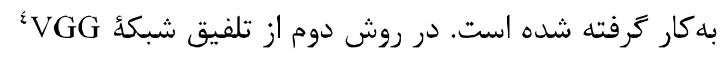

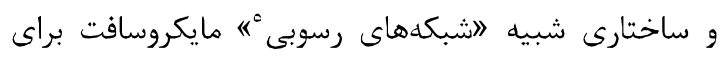

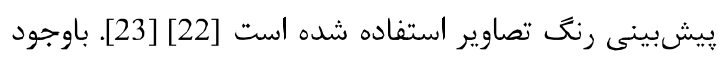

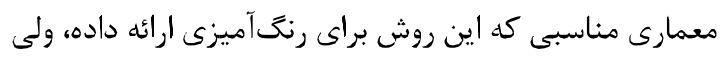

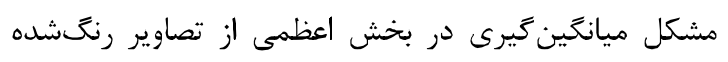

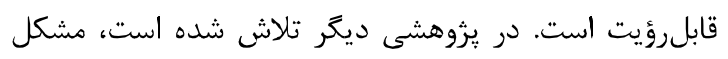

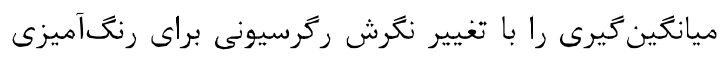

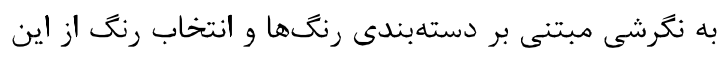

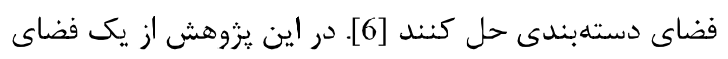

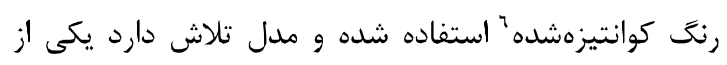

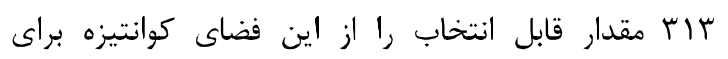

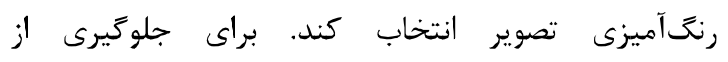

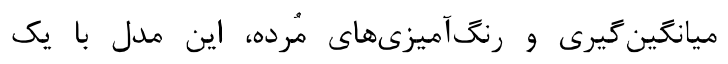

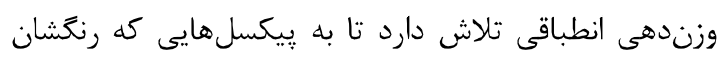

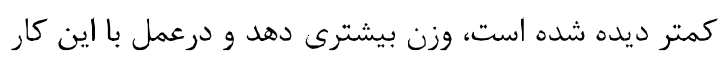
دستههاى رنتخى را متوازن كند.

${ }^{2}$ Learning-based colorization

${ }^{3}$ Hypercolumns

${ }^{4}$ Visual Geometry Group

${ }^{5}$ Residual Nets

${ }^{6} \mathrm{LAB}$
به سمت هدف مورد نظر هدايت مى كند [12]. در شكل (a) المائ)

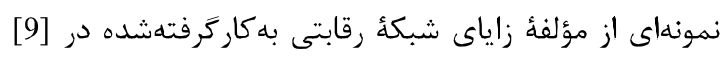
نمايش داده شده است.

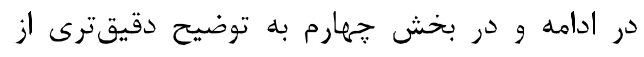
جكَونگى عملكرد الكوريتهم و بجينهسازىها خواهيم برداخت.

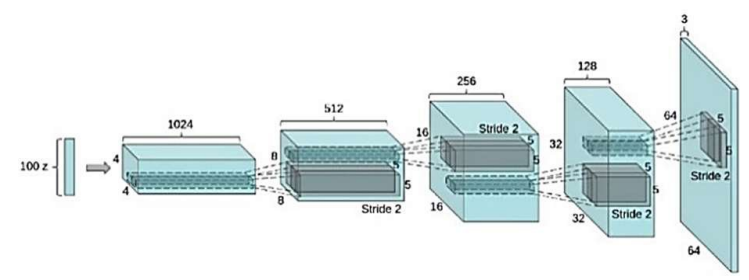

(شكل - ه) : نمونهاى از مؤلفهُ زاياى يك شبكةُ رقابتى

(Figure-5): An example of a generator network in a GAN

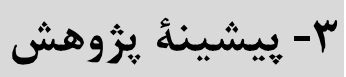

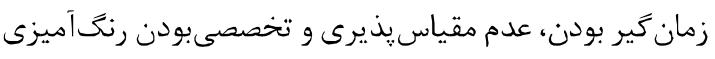

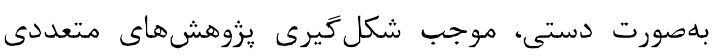

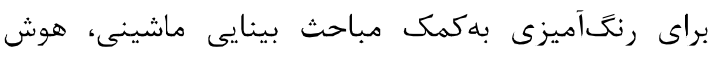

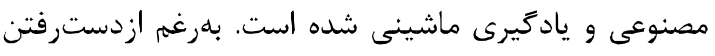
اطلاعات در تصاوير خاكسترى، انسانها قادر بادئ استخراج

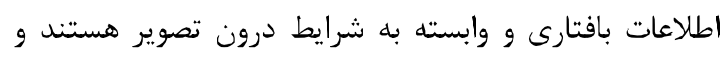

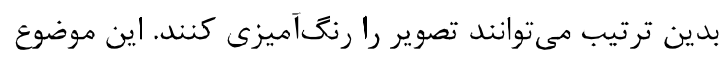

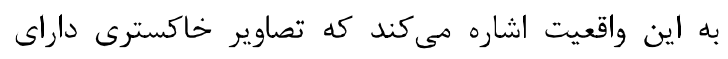

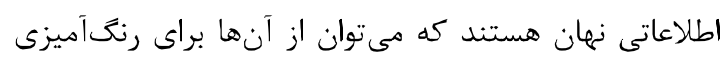

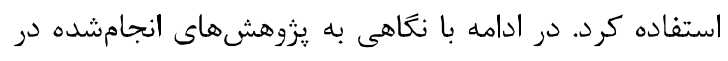

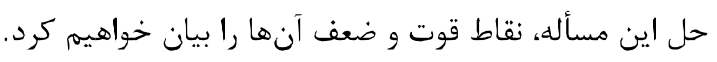

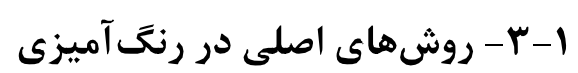

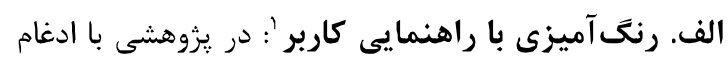

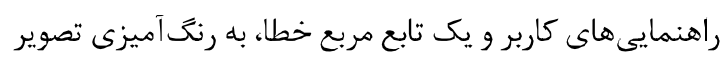

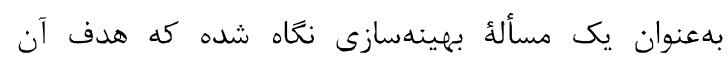

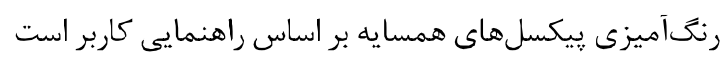

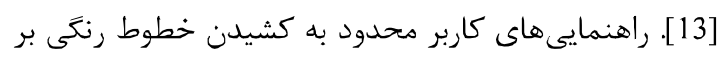

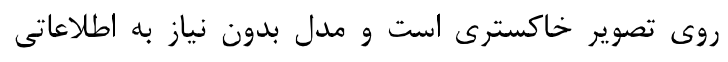

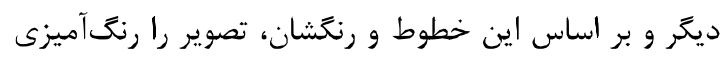

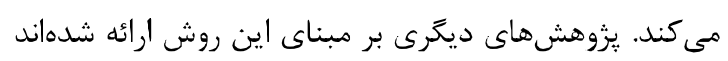

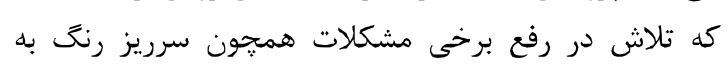

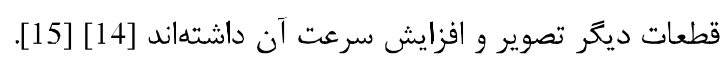

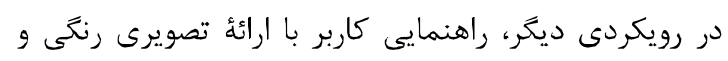

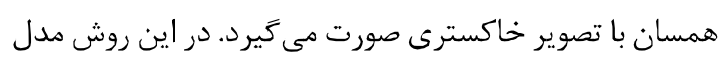

${ }^{1}$ User-guided colorization 
نوشت:

$\mathrm{p}(\mathrm{x} \mid \hat{\mathrm{x}}) \propto \exp \left(-\frac{1}{2}\|\hat{\mathrm{x}}-\mathrm{x}\|_{2}^{2}\right)$ $\log \mathrm{p}(\mathrm{x} \mid \widehat{\mathrm{x}}) \propto-\frac{1}{2}\|\hat{\mathrm{x}}-\mathrm{x}\|_{2}^{2}$ با اعمال لكار يتم، به رابطة زير مر

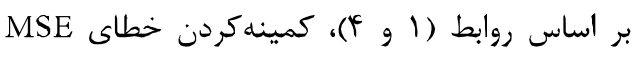

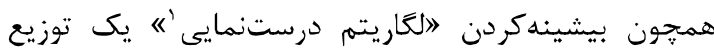

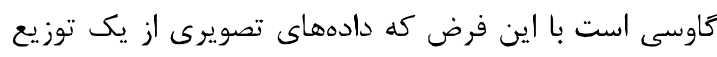

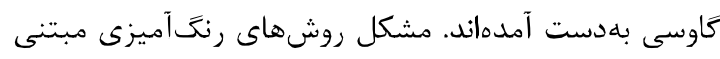

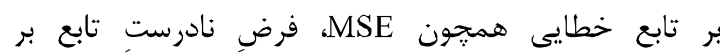

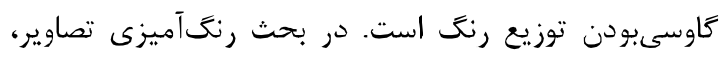

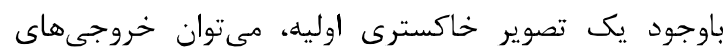

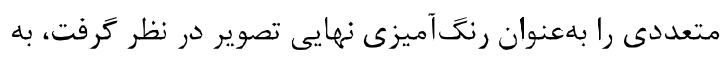

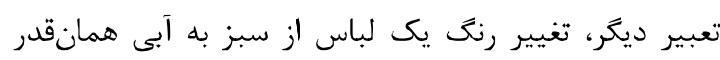

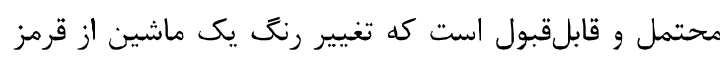

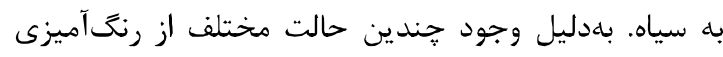

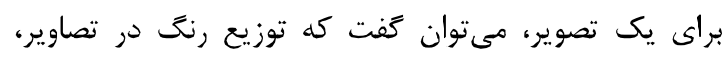

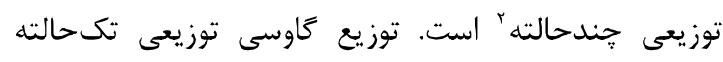

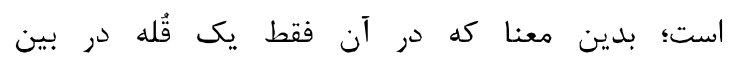

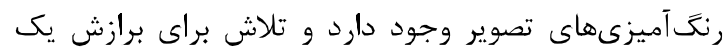

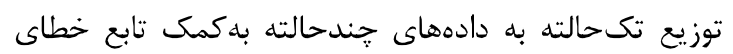

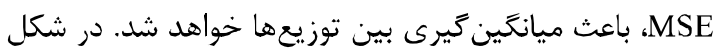
(ع) نمونهاى ساده از اين اتفاق نشان داده شده برئ است:

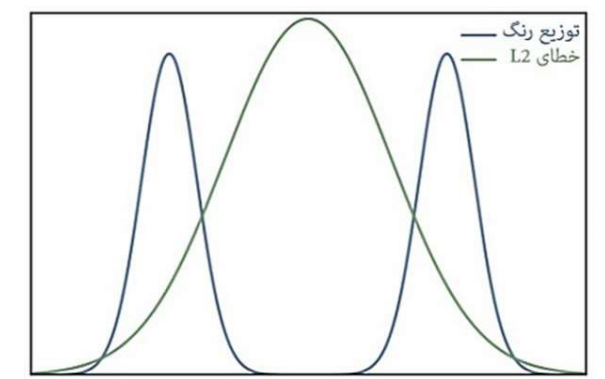

(شكل- (צ): برازش توزيع تك حالته به توزيعهاى جندحالته (Figure-6): Fitting a unimodal distribution to multi-modal data

اكر در هنعام آموزش، تصاويرى را به شبكه دهيم كه

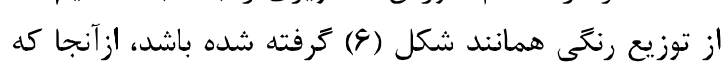

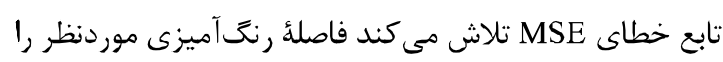

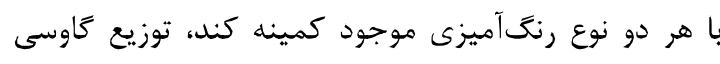

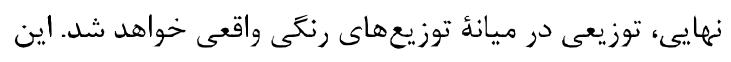

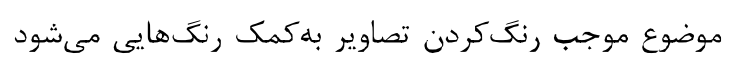

\footnotetext{
${ }^{1}$ Log-Likelihood

2 Multimodal
}

باوجود عمق بالا در بيشتر شبكههاى يادشده و

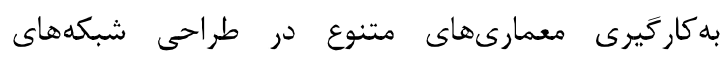

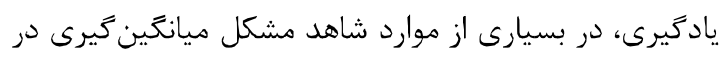

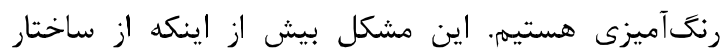

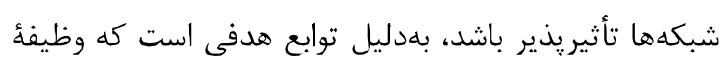

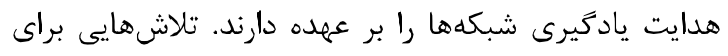

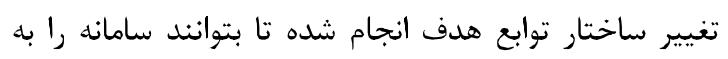

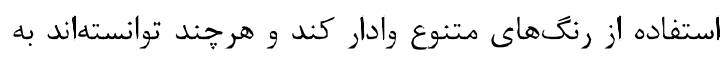

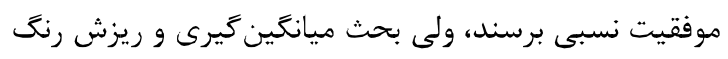

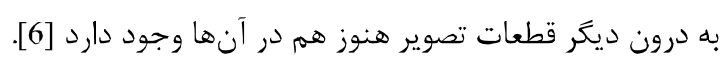

\section{r-r- ميانغينگيرى و ضعف توابع خطاى \\ مبتنى بر ميانگين مربع خطا (MSE)}

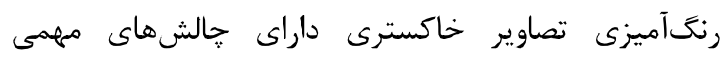

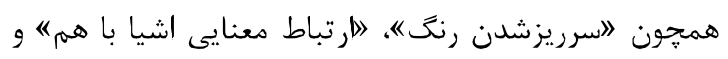
"ميانخين كيرى" است و هدف آن است كه سامانهاى طراحى رانى

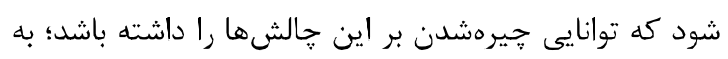

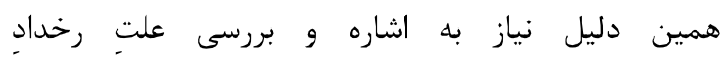

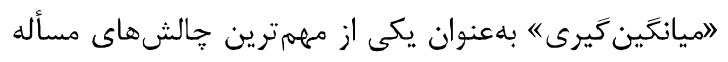

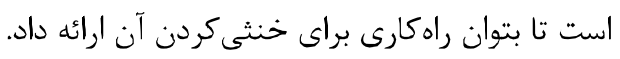

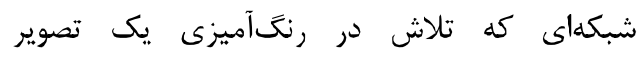

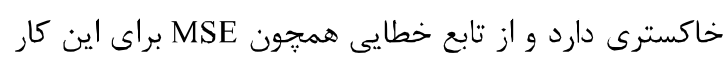

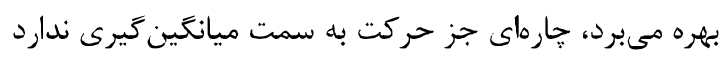

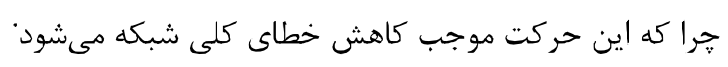

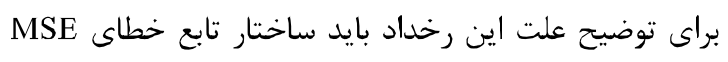

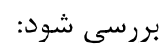

$$
\mathrm{L}=\frac{1}{2 \mathrm{M}} \sum_{\mathrm{i}}^{\mathrm{T}}\left\|\hat{\mathrm{y}}_{\mathrm{i}}-\mathrm{y}_{\mathrm{i}}\right\|_{2}^{2}
$$

كه M تعداد كل تصاوير، T تعداد كل بيكسلهاى تصوير،

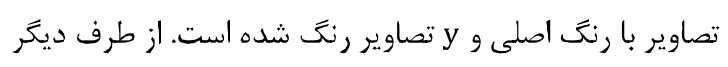
در توزيع تاوسى داريم: تصني

$\mathrm{p}\left(\mathrm{y} \mid \mu, \sigma^{2}\right)=\frac{1}{\mathrm{Z}} \exp \left(-\frac{\|\mu-\mathrm{y}\|_{2}^{2}}{2 \sigma^{2}}\right)$

در اين توزيع Z ثابت هنجارسازى، ب ميانكين و

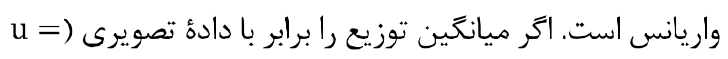
ŷ ناديده بكيريم (جرا كه تأثير آن در توزيعها

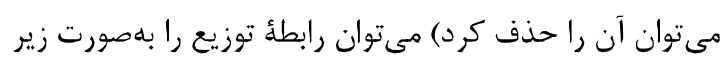


اصلى (يا تصويرى كه رنگَآميزى آن واقعى به نظر مىرسد) داشته باشد. براى اين كار، ابزار مورد استفاده، شبكههاى عصبى عميق (CNN) و شبكهاى زاياى رقابتى ' (GAN)

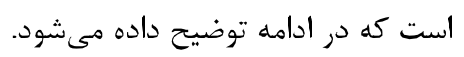
همرجنان كه بيان شد، انسانها بهرغم ازدسترفترفت دهن اطلاعات در تصاوير خاكسترى، قادر به استخراج اطللاعات بافتارى `و وابسته به شرايط درون تصوير هستند تا بر اساس دري آن بتوانند تصوير را بهصورتى نسبى رنغَآميزى كنيند.

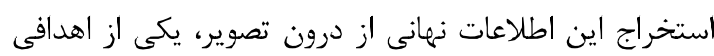

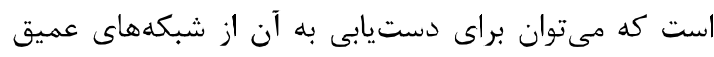

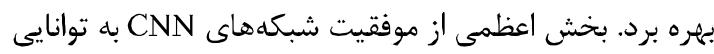

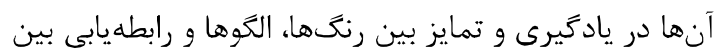
اشكال درون تصاوير برمى

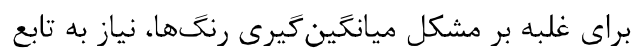

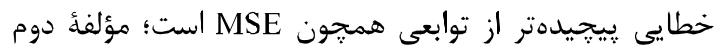
شبكةٔ رقابتى (شبكةٔ تمايزى) كه وظيفهُ تمايزيابى بين تصوير رنكى واقعى و تصوير رنتَآميزى شده را بر عهده دارد، بهعنوان

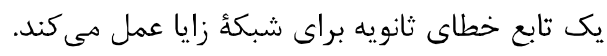

كه "واقعى" به نظر نمىرسند و در بيشتر مواقع حتى بدترين انتخاب ممكن هستند؛ جون كه شبكه درعمل تلاش مي كند رنتهايى را از فضاى رنتآميزى انتخاب كند كه نه در توزيع واقعى نخست و نه در توزيعهاى ديخر بلكه در ميانه همكى رئ آنها هستند.

اين موضوع در رنتَآميزى اشيايى كه توزيع رنت هدن تك حالتهاى دارند (همجون جمن يا دريا) تأثير جندانى ندارد

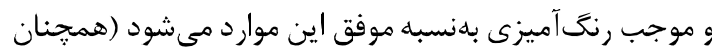

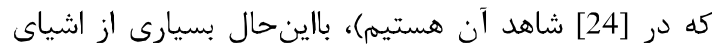

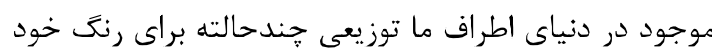

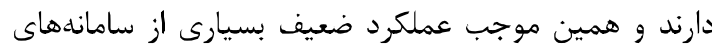

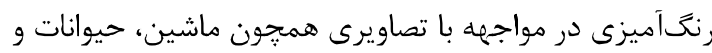
انسان ها مىشود [7].

\section{F- مواد و روشها} همرجنان كه اشاره شد در اين مقاله به دنبال آن هستيم كه

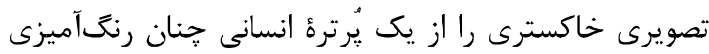

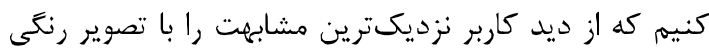

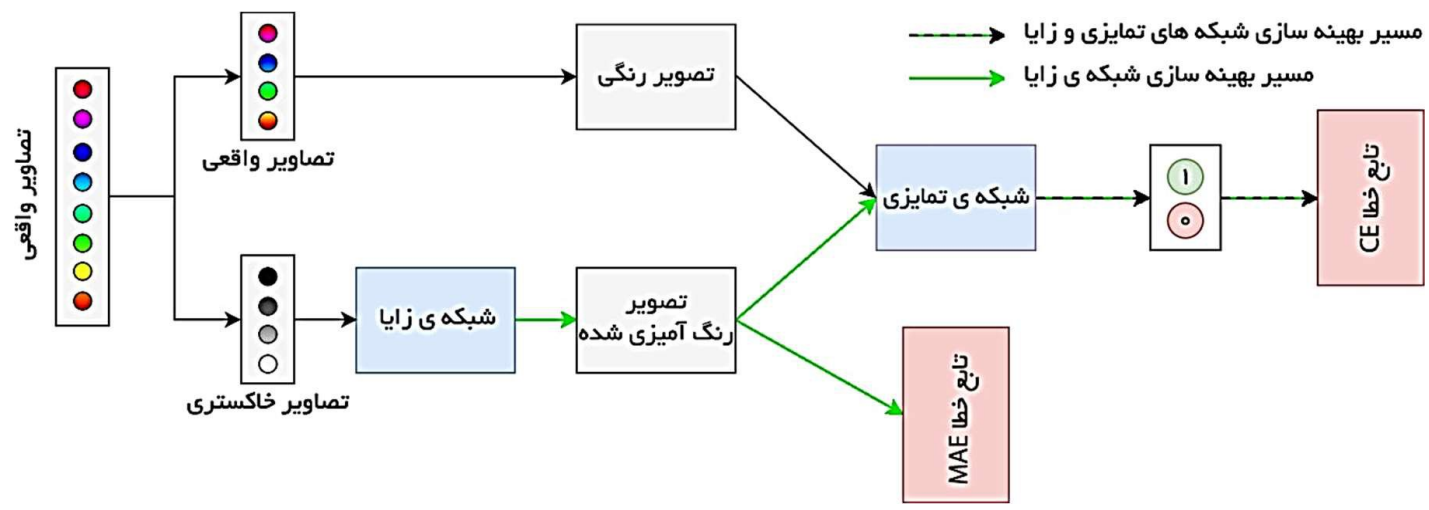

(شكل - ( ): ساختار شبكهُ زاياى رقابتى براى رنكى آميزى تصاوير

(Figure-7): GAN architecture for colorizing images

است كه به هنغام تصويربردارى، از توزيع احتمال خاص آن محيط نمونهبردارى مىشود. در اين زئوهش تمركز بر روى

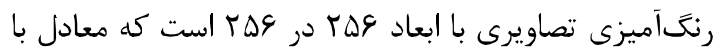

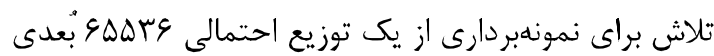

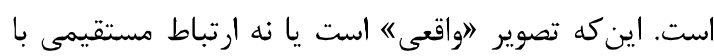

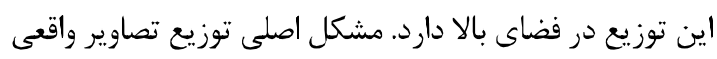

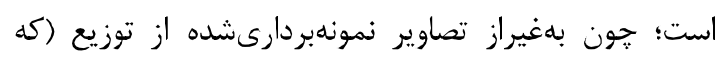

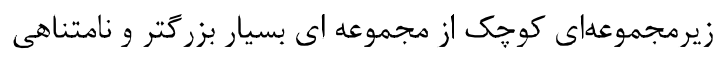

\footnotetext{
${ }^{1}$ Generative $\Lambda$ dversarial Network

${ }^{2}$ Contextual Clues
}

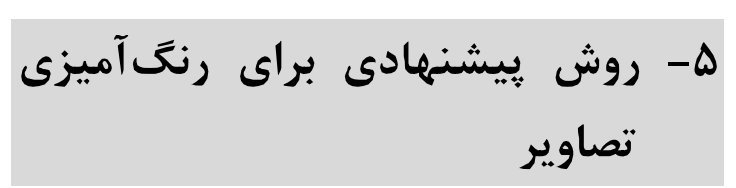

رنخآميزى يك تصوير خاكسترى را مىتوان تلاشى براى

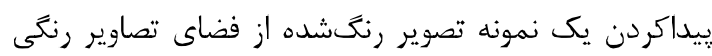
يك توزيع احتمالى در نظر گرفت. اين موضوع در لحظاتى كه رئه در حال خلق يك تصوير هستيم صادق است. بهعنوانمثال

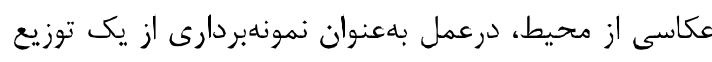

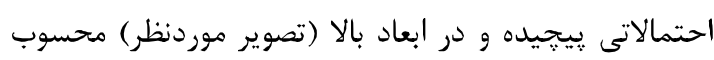

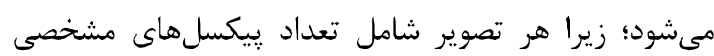


استفاده شده است. اين معمارى بهدليل ساختار رسوبى خود

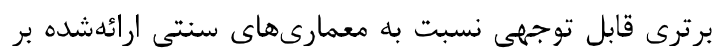

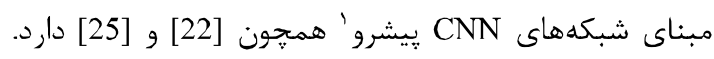
معمارى هاى سنتى شبكههاى CNN در وظايف دستهبندى و

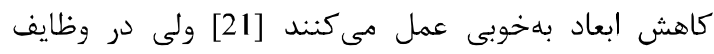

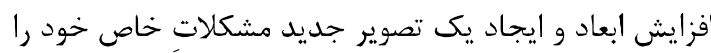

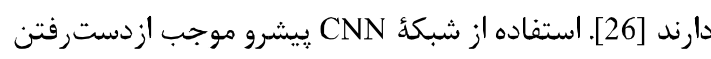

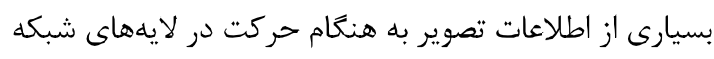

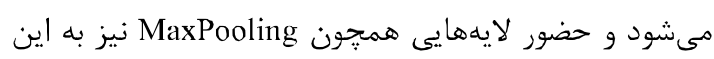

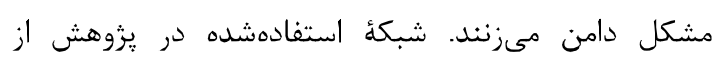

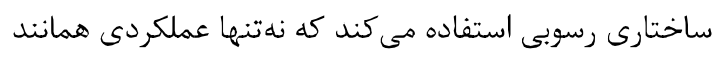

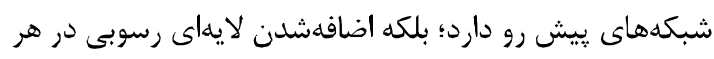

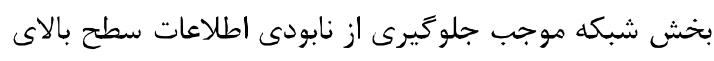

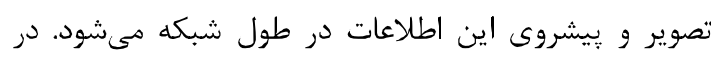

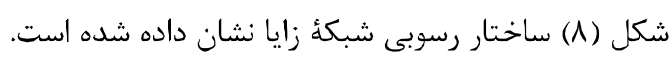

از دنياى اطراف است)، هيج اطلاعاتى در مورد ساختار واقعى

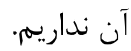

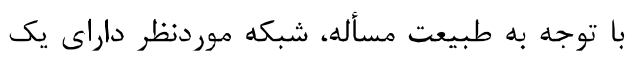
ورودى x (تصوير خاكسترى) و خروجى z (تصوير رنغ شده)

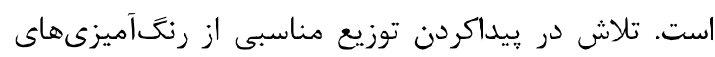

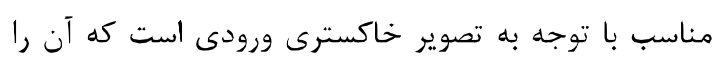

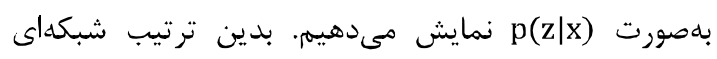

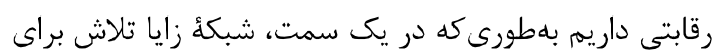

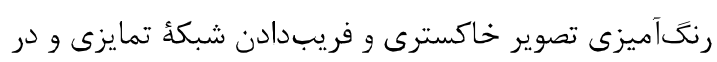

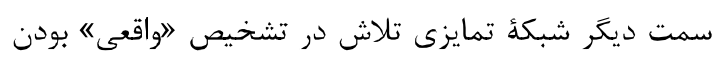

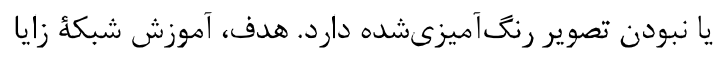

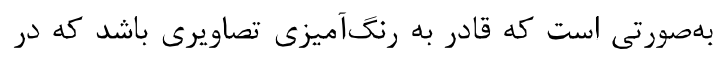

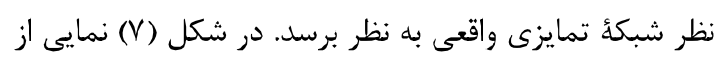

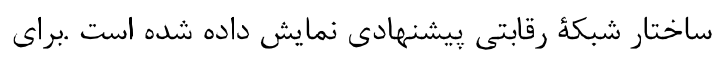

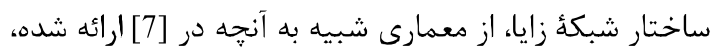

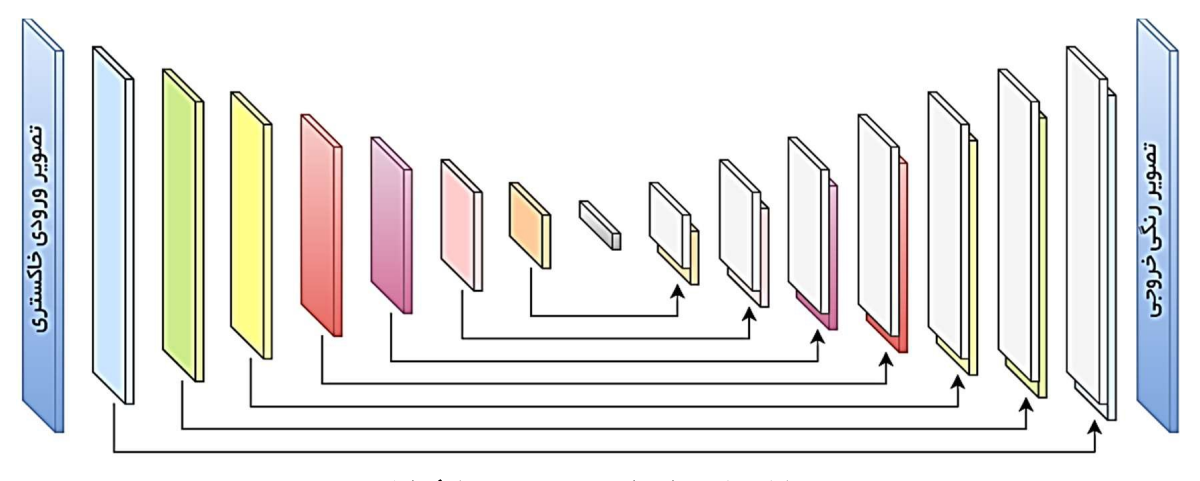

(شكل-1): ساختار رسوبى در شبكئ زايا

(Figure-8): Residual architecture in the generator network

زايا را بهصورت تلفيق تابع Cross Entropy (مرتبط با شبكءٔ (دئ

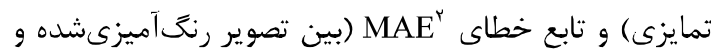
تصوير واقعى) تعريف مى كنيه: تمئم

$\mathrm{G}_{\text {Loss GAN }}=-\log (\mathrm{D}($ Colored Image $))$

$\mathrm{G}_{\text {Loss L1 }}=\|$ Real Image - Colored Image $\|_{1}$

$G_{\text {Loss Total }}=0.5 G_{\text {Loss } G A N}+0.5 \mathrm{G}_{\text {Loss L1 }}$

در اين روابط Colored Image تصوير رنتىآميزى شده توسط سامانه و Real Image تصوير اصلى داراى رنت است.

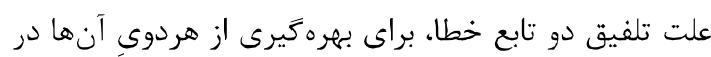
رنتآميزى تصاوير است. خطاى GAN از رنت آميزى دهاى مُرده شبكه بِيش ريرى مى كند و خطاى L1 ساختار كلى

${ }^{\mathrm{I}}$ Feedforward

${ }^{2}$ Mean Absoulute Error
تابع هدف شبكة زايا تلفيقى از دو تابع هدف يكى

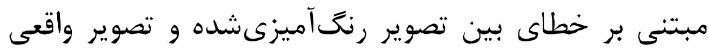

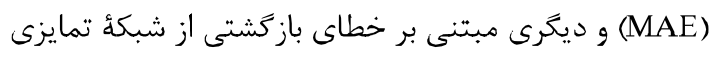

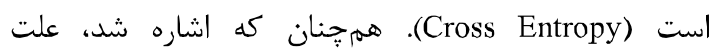

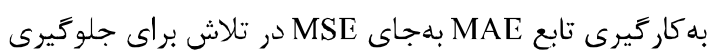
از ماتشدن تصاوير ايجادشده (مشخصة شناختهشدهاى از از

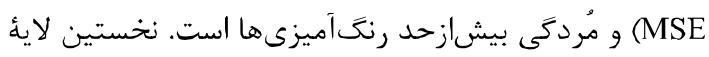

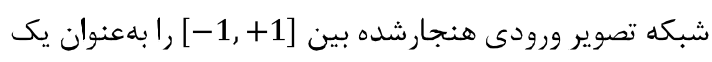

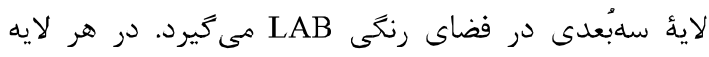

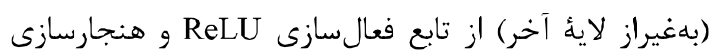
BatchNorm ديخر لايهها از يك تابع فعالسازى تانزانت هاييربوليك (Tanh) استفاده مى كند تا مقادير ايجادشده توسط شبكهُ زايا را به بازه [1, +1-1 [حدود كند. از سوى ديخر تابع هدف نهايى شبكة 
تمايزى بلهرعت و بهخوبى جَّونكَى تمايز بين تصاوير

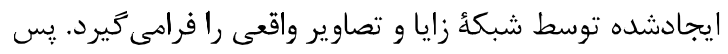

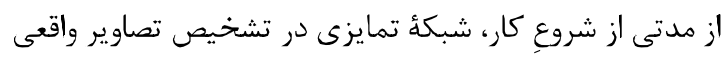

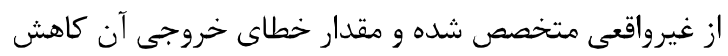

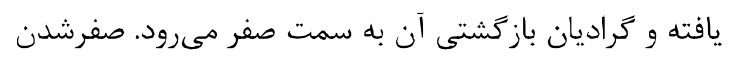

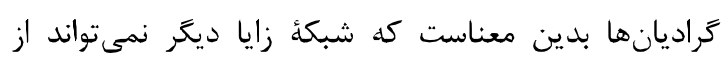

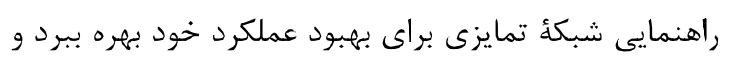

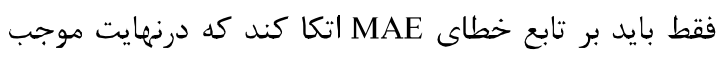

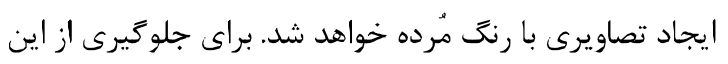

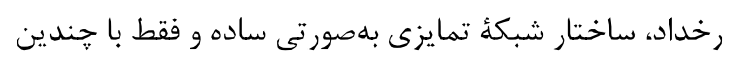

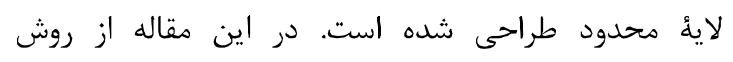

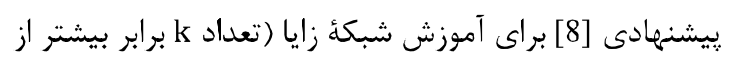

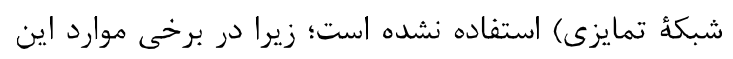
موضوع بر بيشرفت يادكيرى شبكه اثر منفى دارد.
تصوير را حفظ مى كند و مانع ريزش رنغَ از يكى ناحيه به ناحية نامناسب همسايه مى رشود.

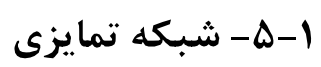

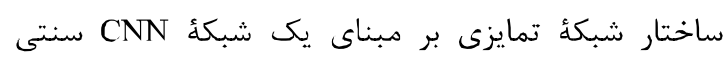

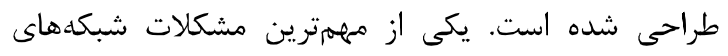

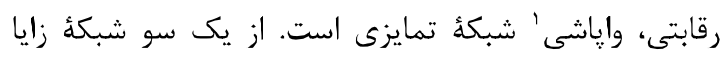

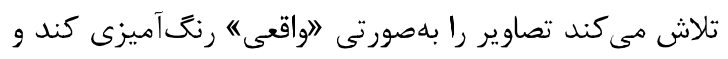

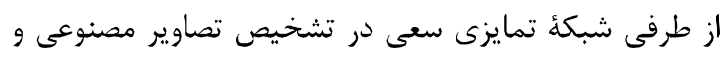

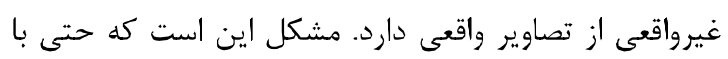

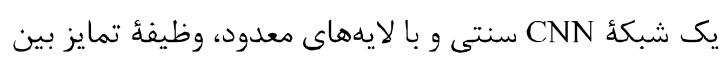

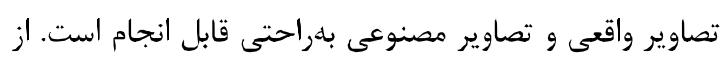

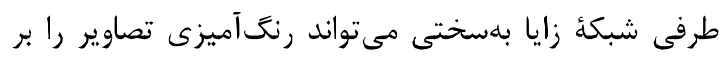

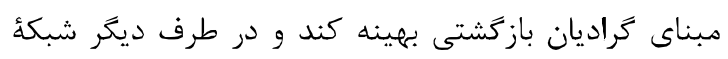

\section{for number of iterations do}

- Sample $\boldsymbol{m}$ real color images $\left\{x^{(1)}, x^{(2)}, \ldots, x^{(m)}\right\}$ from real color distribution $p_{\text {data }}(x)$

- Generate $\boldsymbol{m}$ fake colorized images $\left\{z^{(1)}, z^{(2)}, \ldots, z^{(m)}\right\}$ from real gray distribution $p_{\text {data }}(x)$

- Update the discriminator:

$$
\nabla_{\theta_{d}} \frac{1}{m} \sum_{i=1}^{m}\left[\log \left(D\left(x^{(i)}\right)+\log \left(1-D\left(G\left(z^{(i)}\right)\right)\right)\right)\right]
$$

- Generate $\boldsymbol{m}$ fake colorized images $\left\{z^{(1)}, z^{(2)}, \ldots, z^{(m)}\right\}$ from real distribution $p_{\text {data }}(x)$

- Update the generator:

$$
\nabla_{\theta_{g}} \frac{1}{m} \sum_{i=1}^{m}\left[\log \left(1-D\left(G\left(z^{(i)}\right)\right)\right)\right]
$$

$$
\text { (شكل - (9): شبهكد ياد }
$$

(Figure-9): Pseudo-code of the two networks

شبكة زايا) را ياد مى گيرد. در اينجا هدف شبكة تمايزى دو نكتهٔ زير است:

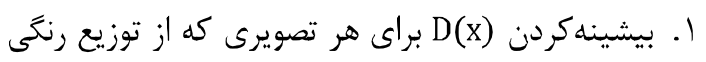

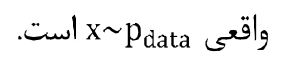

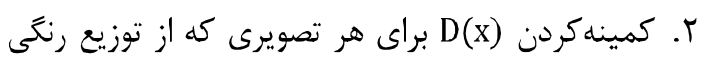

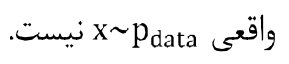

اين دو هدف را مىتوان بلصورت نيست خلاصُٔ زير در نظر

$\min _{G} \max _{\mathrm{D}} \mathbb{E}_{\mathrm{x} \sim \mathrm{p}_{\text {data }}} \log [\mathrm{D}(\mathrm{x})]+\mathbb{E}_{\mathrm{z} \sim \mathrm{p}_{\mathrm{z}}} \log [1-\mathrm{D}(\mathrm{G}(\mathrm{z}))]$

شبهكد نهايى براى يادكيرى دو شبكه بهصورت شكل (9)

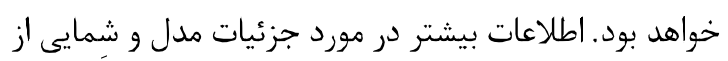

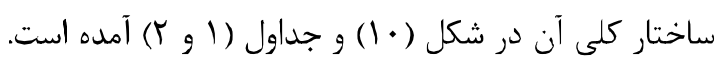

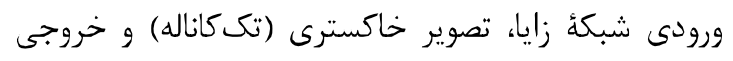
شبكة زايا تصوير رنغآميزىشدهُ جعلى (تصوير سه كاناله) r-ه - تابع هدف

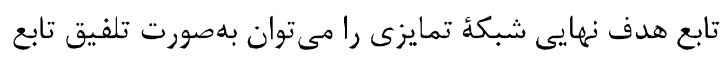
Cross Entropy

$$
\begin{aligned}
& \mathrm{D}_{\text {Loss Real }}=-\log (\mathrm{y} \mid \text { Real Image }) \\
& \mathrm{D}_{\text {Loss Fake }}=-\log (1 \\
& \quad-\mathrm{y} \mid \text { Colored Image }) \\
& D_{\text {Loss Total }}=0.5 D_{\text {Loss Real }}+0.5 \\
& D_{\text {Loss Fake }}
\end{aligned}
$$

y

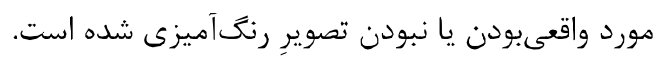

$$
\text { ب- اله- الكوريتم يادكيرى }
$$

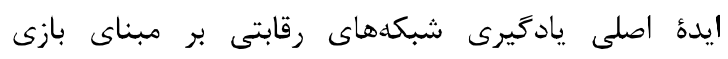
MinMax

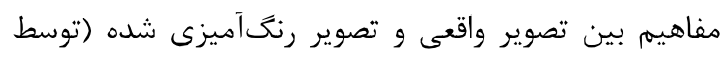

${ }^{1}$ Collapse 
به كار گيرى حندين مجموعه دادئ متفاوت، تلاش براى يوشش

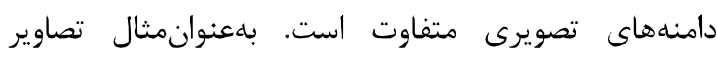

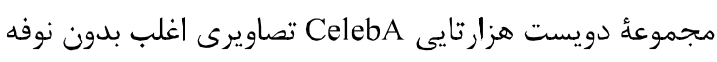

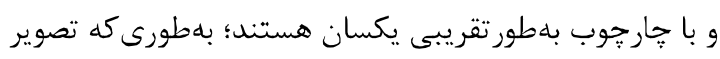

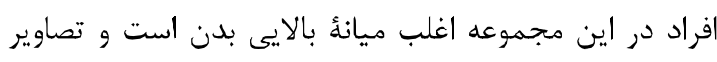

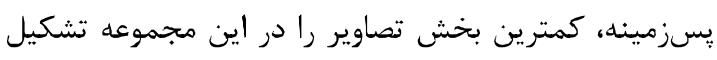

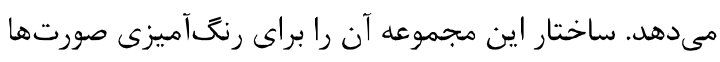

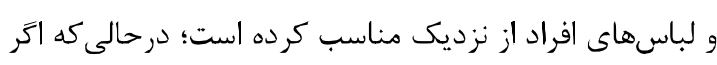

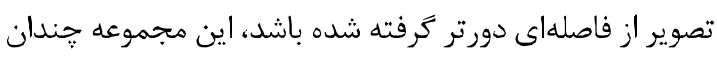

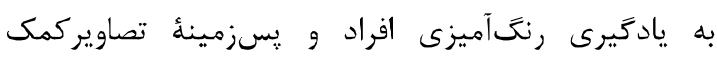
نمى كند.
است. ورودى شبكة تمايزى نيز تلفيق هر دو تصوير با

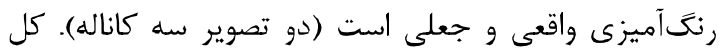

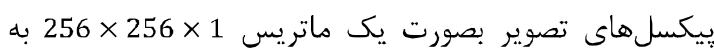

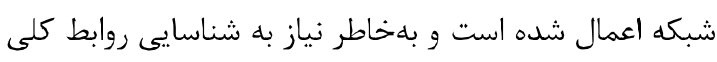

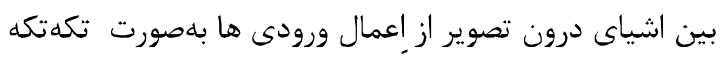

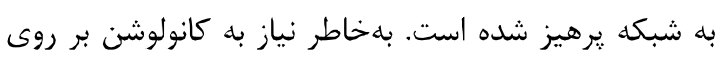

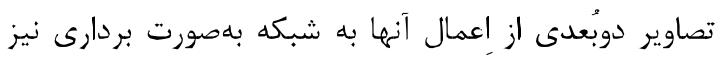

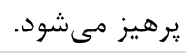

\section{و- بيادهسازى و ارزيابى عملكرد سامانه}

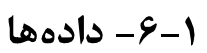

براى آموزش شبكه، تلفيقى از مجموعه دادههاى إدهاى

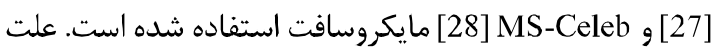

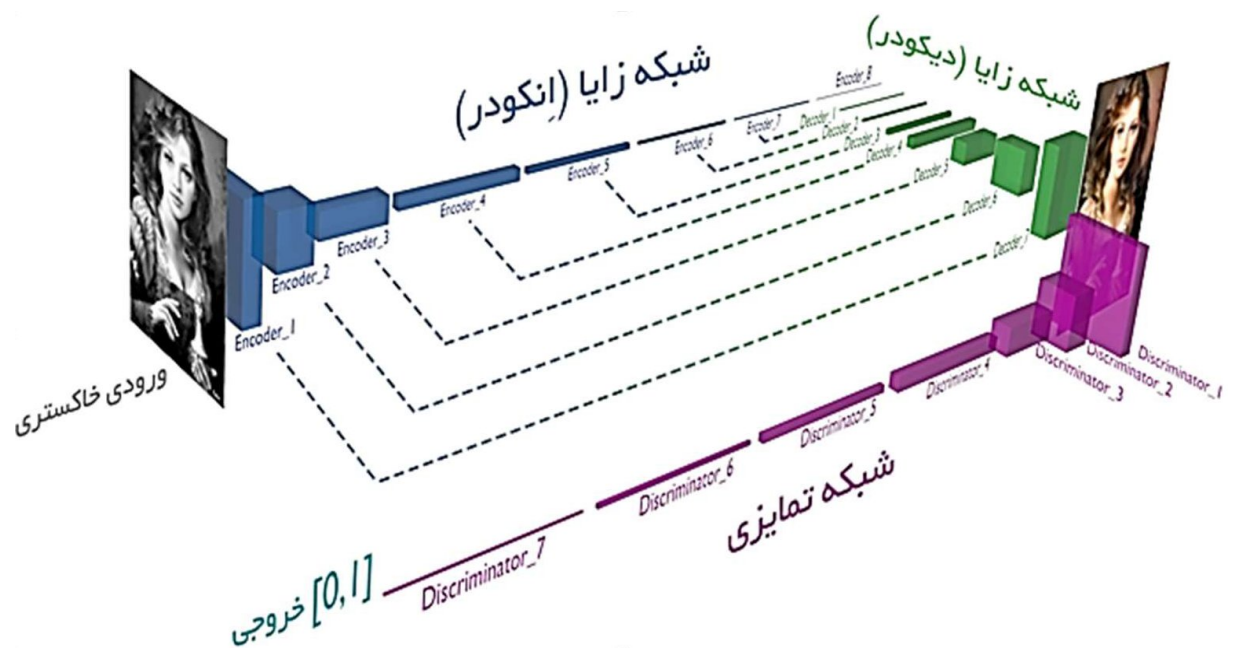

(شكل-•) - (1): ساختار شبكه

(Figure-10): Network Architecture

(جدول -1): جزئيات شبكه زايا

(Table-1): Generator network details

\begin{tabular}{|c|c|c|c|c|}
\hline 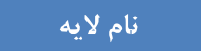 & اندازه تصوير & ت تجداد كانال & ل نوع كاذال & ت توضيحات \\
\hline تصويرِ خاكسترى & $256 \times 256$ & 1 & & $\begin{array}{l}\text { كانال L از خوير خاكترى } \\
\text { LA*B* }\end{array}$ \\
\hline Encoder_1 & $128 \times 128$ & 64 & Conv + LReLU & \\
\hline Encoder 2 & $64 \times 64$ & 128 & Conv + BatchNorm + LReLU & \\
\hline Encoder_3 & $32 \times 32$ & 256 & Conv + BatchNorm + LReLU & \\
\hline Encoder 4 & $16 \times 16$ & 512 & Conv + BatchNorm + LReLU & \\
\hline Encoder 5 & $8 \times 8$ & 512 & Conv + BatchNorm + LReLU & \\
\hline Encoder_6 & $4 \times 4$ & 512 & Conv + BatchNorm + LReLU & \\
\hline Encoder 7 & $2 \times 2$ & 512 & Conv + BatchNorm + LReLU & \\
\hline Encoder_ 8 & $1 \times 1$ & 512 & Conv + BatchNorm + LReLU & \\
\hline Decoder_1 & $2 \times 2$ & $512+512$ & DeConv + BatchNorm + ReLU & تلفيق با Fncoder 7 \\
\hline Decoder_2 & $4 \times 4$ & $512+512$ & DeConv + BatchNorm + ReLU & تلفيق با Encoder 6 \\
\hline Decoder 3 & $8 \times 8$ & $512+512$ & DeConv + BatchNorm + ReLU & تلفيق با Encoder 5 \\
\hline Decoder_4 & $16 \times 16$ & $512+512$ & DeConv + BatchNorm + ReLU & تلفيق با Fncoder 4 \\
\hline
\end{tabular}




\begin{tabular}{|c|c|c|c|c|}
\hline Decoder 5 & $32 \times 32$ & $256+256$ & DeConv + BatchNorm + ReLU & تلفيق با Encoder 3 \\
\hline Decoder_6 & $64 \times 64$ & $128+128$ & DeConv + BatchNorm + ReLU & تلفيق با Encoder 2 \\
\hline Decoder_ 7 & $128 \times 128$ & $64+64$ & DeConv + BatchNorm + ReLU & تلفيق با Encoder 1 تل \\
\hline Decoder_ 8 & $256 \times 256$ & 2 & DeConv + Tanh & كا:نالهاى \\
\hline تصويرِ رنك شده & $256 \times 256$ & 3 & 3 & $\begin{array}{c}\text { تلفيق كانالهاى } \\
\text { L, A*, B* }\end{array}$ \\
\hline
\end{tabular}

(جدول - (r): جزئيات شبكه تمايزى

(Table-2): Discriminator network details

\begin{tabular}{|c|c|c|c|c|}
\hline 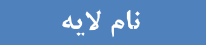 & اندازه تصوير & تعداد كازال & نوع كانال & توضيحات \\
\hline تصويرِ رنَ شله & $256 \times 256$ & $3+3$ & & رتلفيق دو تصويرِ \\
\hline Discriminator_ 1 & $128 \times 128$ & 64 & Conv + LReLU & \\
\hline Discriminator $\_2$ & $64 \times 64$ & 128 & Conv + BatchNorm + LReLU & \\
\hline Discriminator 3 & $32 \times 32$ & 256 & Conv + BatchNorm + LReLU & \\
\hline Discriminator $\_4$ & $16 \times 16$ & 512 & Conv + BatchNorm + LReLU & \\
\hline Discriminator_5 & $8 \times 8$ & 512 & Conv + BatchNorm + LReLU & \\
\hline Discriminator _ 6 & $4 \times 4$ & 512 & Conv + BatchNorm + LReLU & \\
\hline Discriminator $\_7$ & $2 \times 2$ & 512 & Conv + BatchNorm + LReLU & \\
\hline مقدإِ خروجى & $1 \times 1$ & 1 & Conv + Sigmoid & خروجى بين ·و 1 \\
\hline
\end{tabular}

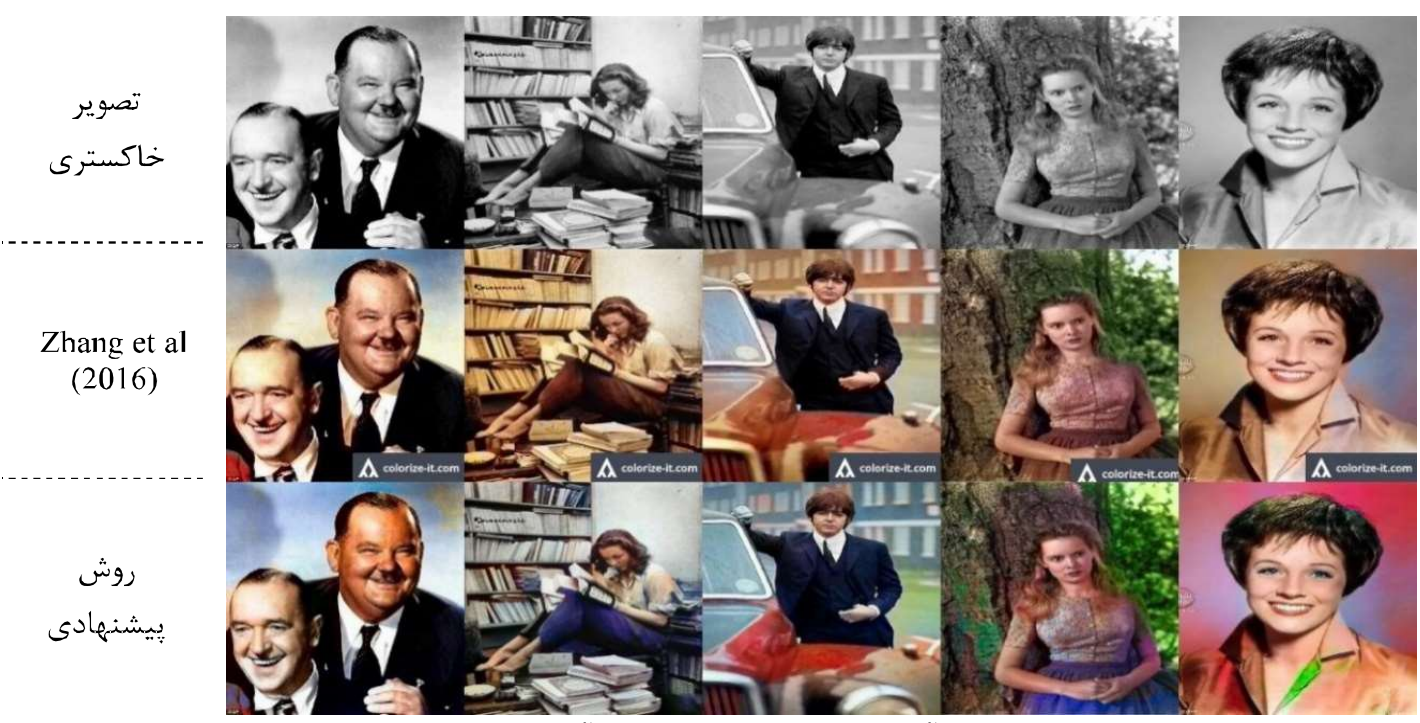

(شكل -11): رنك آميزى تصاويرى كه رنت واقعى آنها موجود نيست

(Figure-11): Colorized images without any "real" color available

لحاظ رنتَآميزى و هم از لحاظ بهكارگيرى در ساختار شبكه دارد [24]. علاوهبراين كانال L در اين فضا درعمل تصوير خاكسترى (ميزان شدت نور) موردنظر ماست كه ميتوان آن آن را بهعنوان ورودى شبكه در نظر كرفت و دو كانال A و B نيز كه رنتبندى تصوير را رقمى مىزنند، خروجى موردنظرمان از

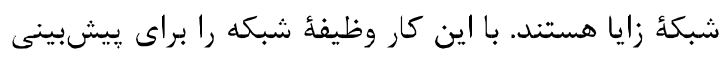

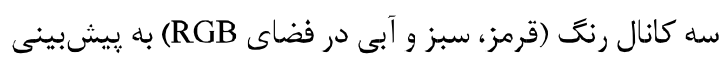
دو كانال (A و B B) تقليل دادهايه.

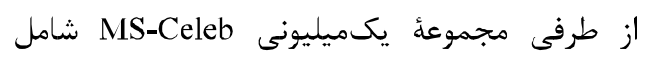

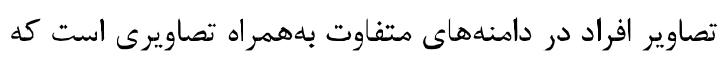

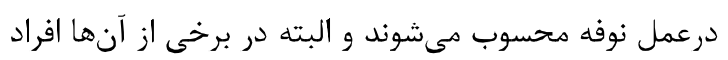

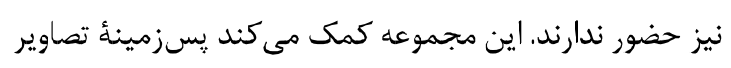
بهتر رنتىآميزى شود. براى ايجاد توازن بين دور مجموعه،

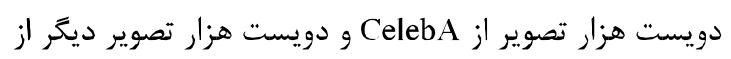
MS-Celeb كاهش يافته است. فضاى رنكى تصاوير را از RGB به فضاى أن

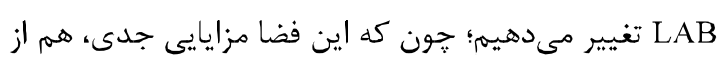




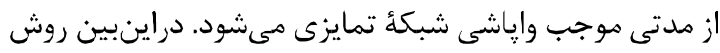
ץ-9- آزمايش تجربى

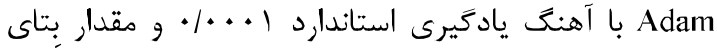

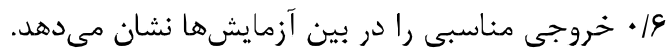

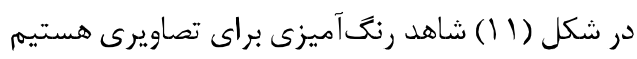

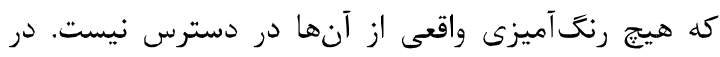

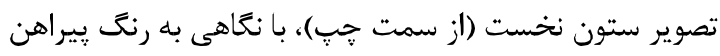

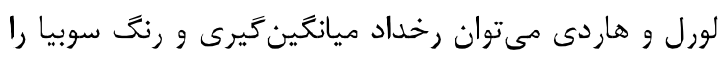

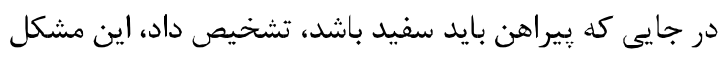

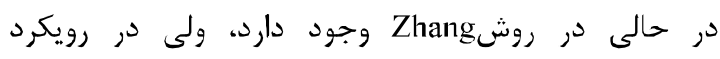

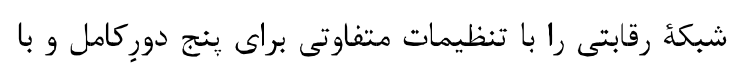

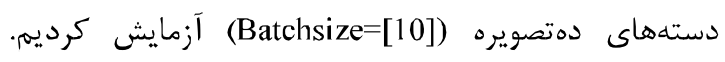

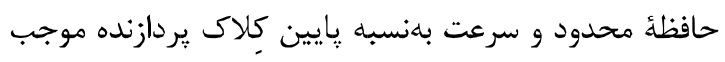

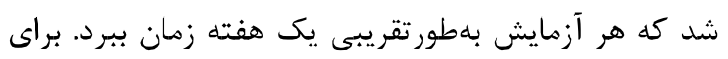

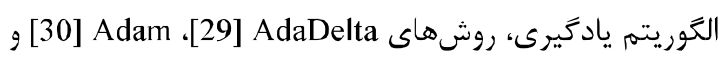
بر برسى شدند. تنظيم دستى و مناسب آهنتِ يادكيرى

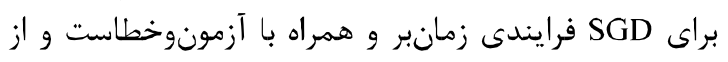

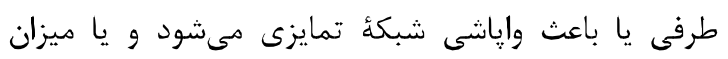

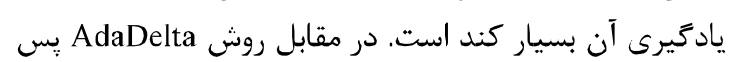

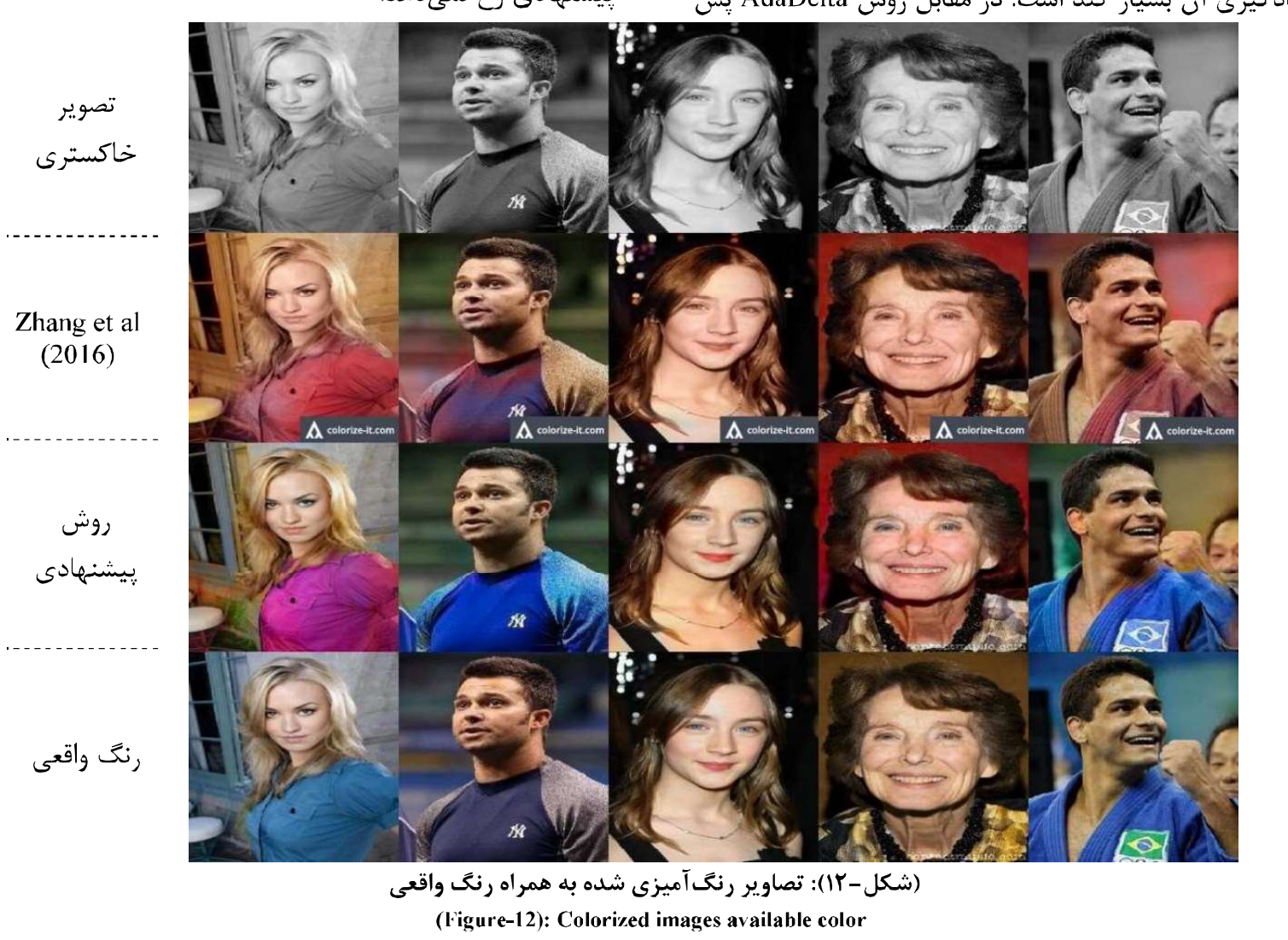

درخت شناسايى كند؛ ولى بهاشتباه بدنهُ درخت را نيز همانند

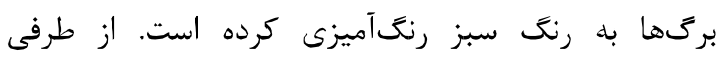

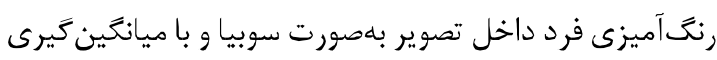

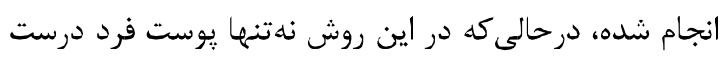

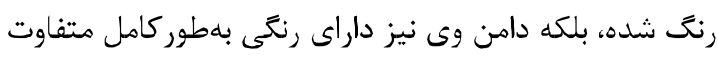

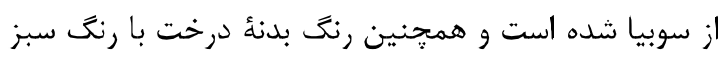

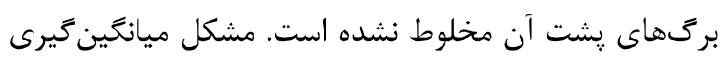

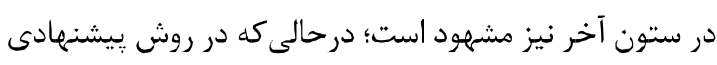

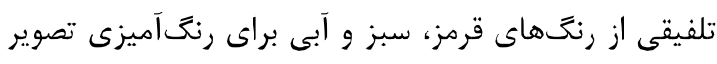

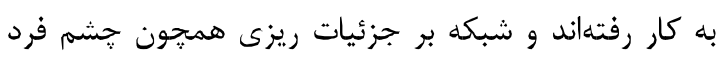
(سبز رنگ) نيز دقت يافته است. در شكل (r) (I) شاهد
در تصوير ستون دوم، شبكه به هيجوجه نتوانسته عناصر

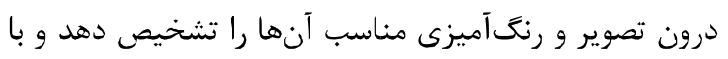

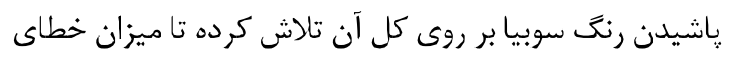

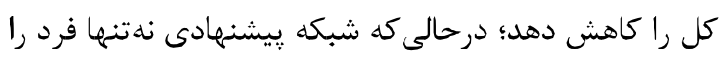

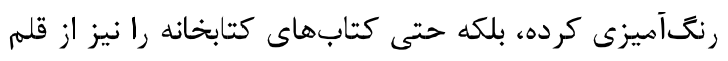

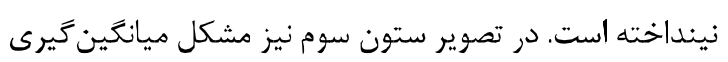

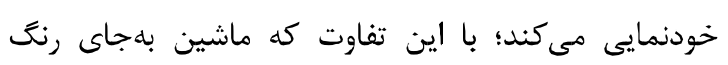

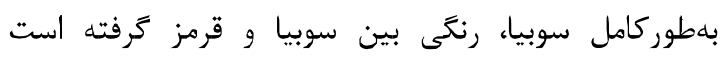

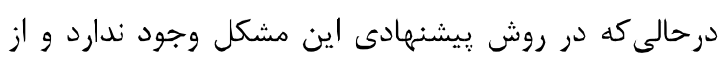

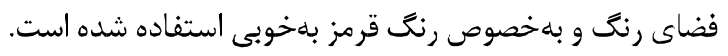

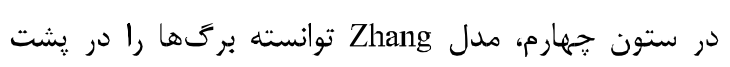


باوجود عملكرد مناسب شبكه در بسيارى از تصاوير كه

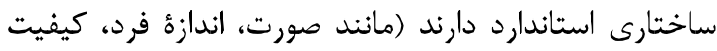

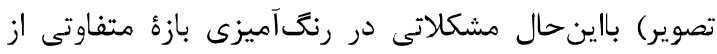
تصاوير نيز وجود دارد. بهعنوانمثال در ستون نخست (از سمت بـاني

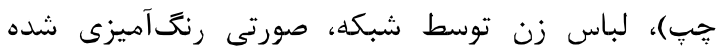

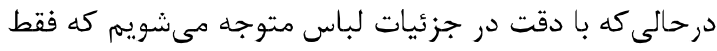

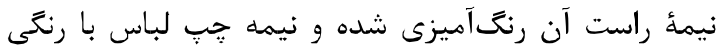

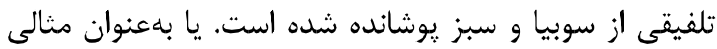

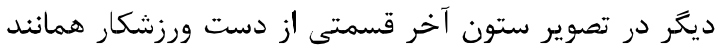

رنكآميزى براى تصاويرى هستيم كه نسخء واقعى آنها موجود است.

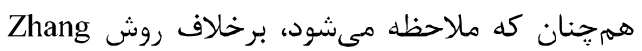

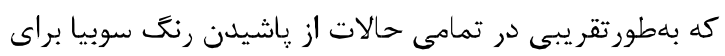

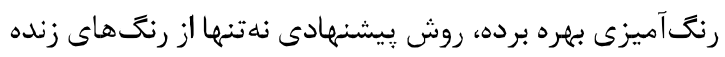

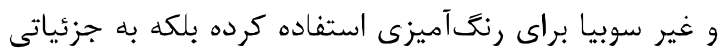
همجون رنخ جشم و لبها نيز توجه شايانى شده است تأت

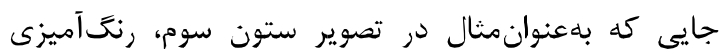

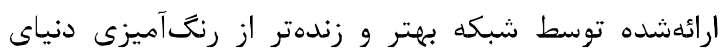

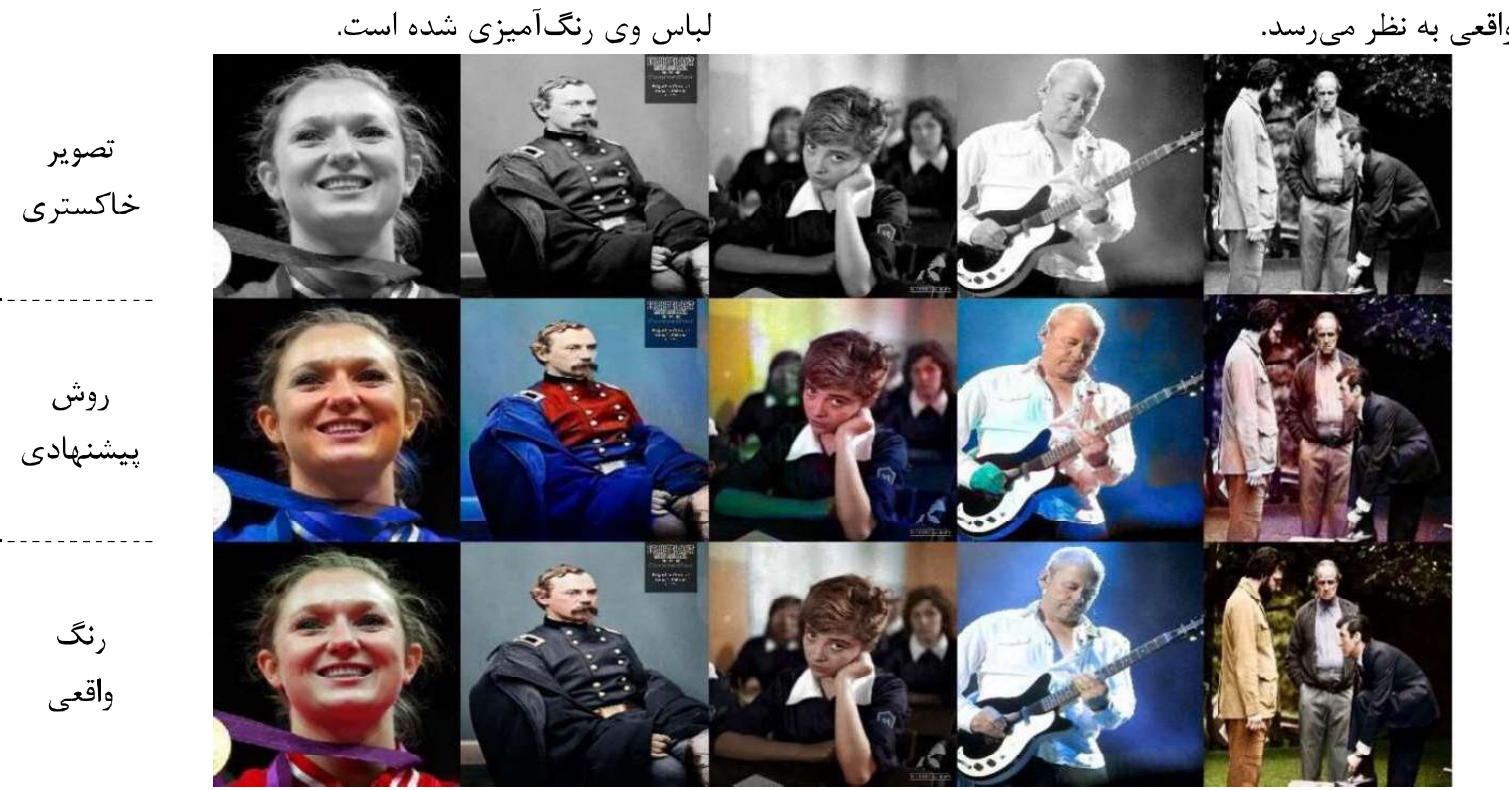

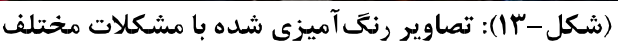

(Figure-13): Common problems in colorization

بهمك Adobe Photoshop رنت شده است) بالينحال

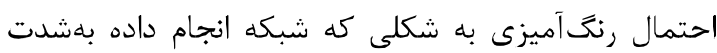

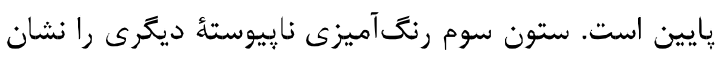

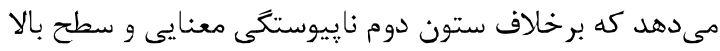

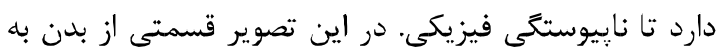

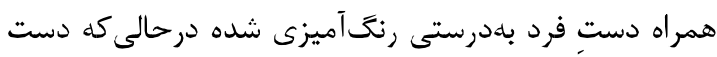

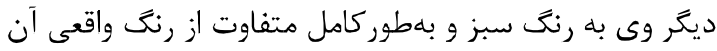

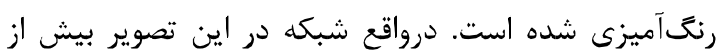

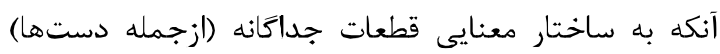

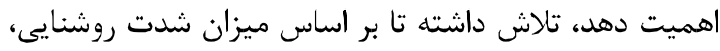

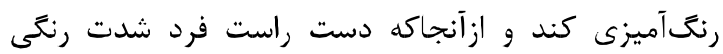

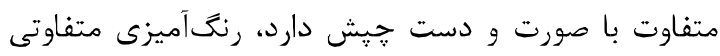

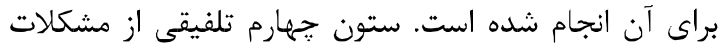

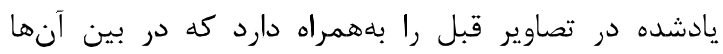

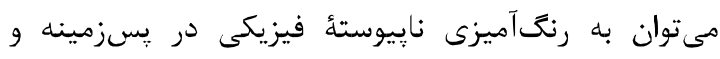

در شكل (rا I) نمونههايى منتخب از عملكرد ضعيف

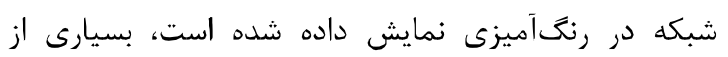

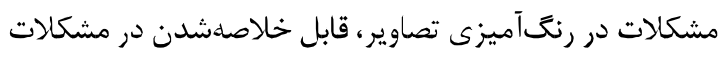
يادشده در اين شكل است. در ستون نخست (از سمت جِّ)، شاهد ورزشكارى

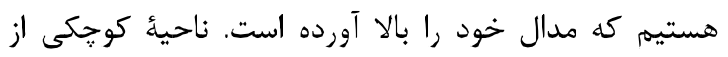

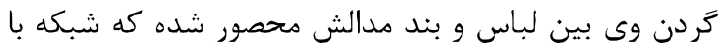

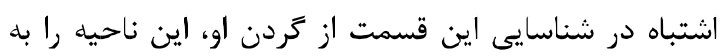

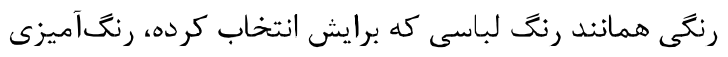

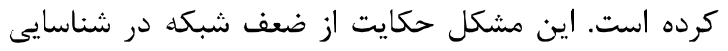

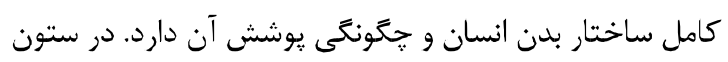

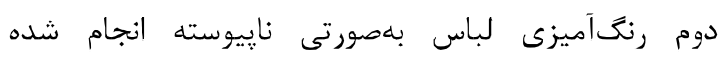

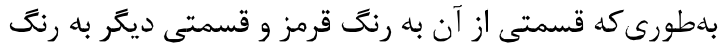
آبى در آمده است، باينكه تصوير رنتى اين ستون، آنس تصويرى

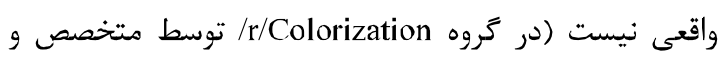


قطعات كليدى تأثيركذارى همجِون انباشتهشدن برى درختان

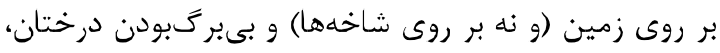

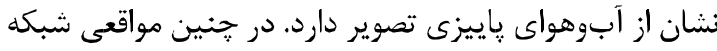

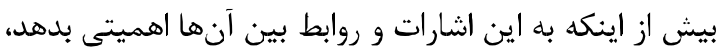

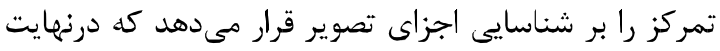

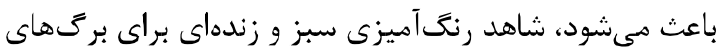

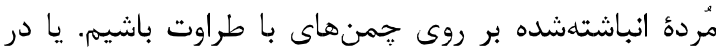

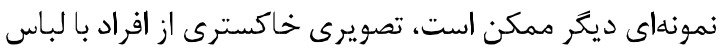

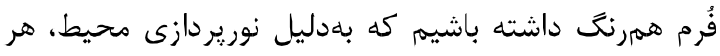

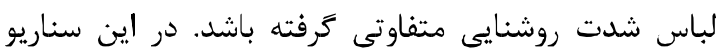

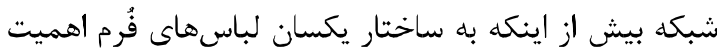

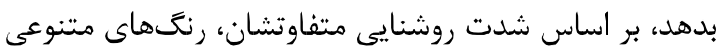

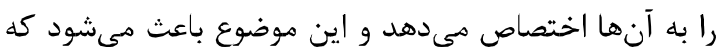

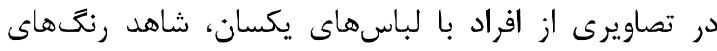
متفاوتى از آبى و قرمز تا سبز و صورتى إنى باشيه.
همجنين رنكآميزى نايِيوستة مفهومى براى دست فرد (به

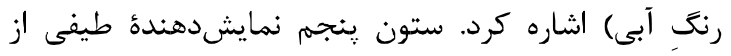

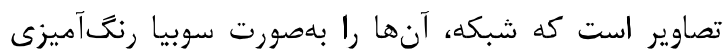
مى كند. در اين تصاوير شبكه نتوانسته اجزاى تأثيركذار در

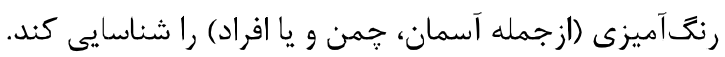

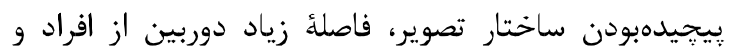

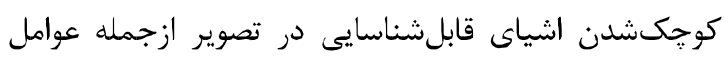

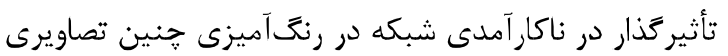

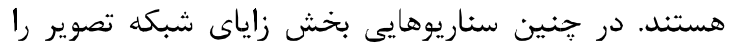

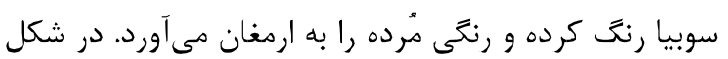

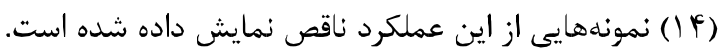

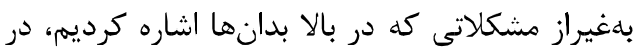

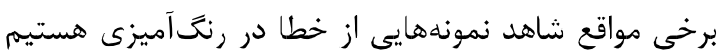

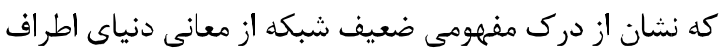

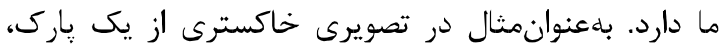

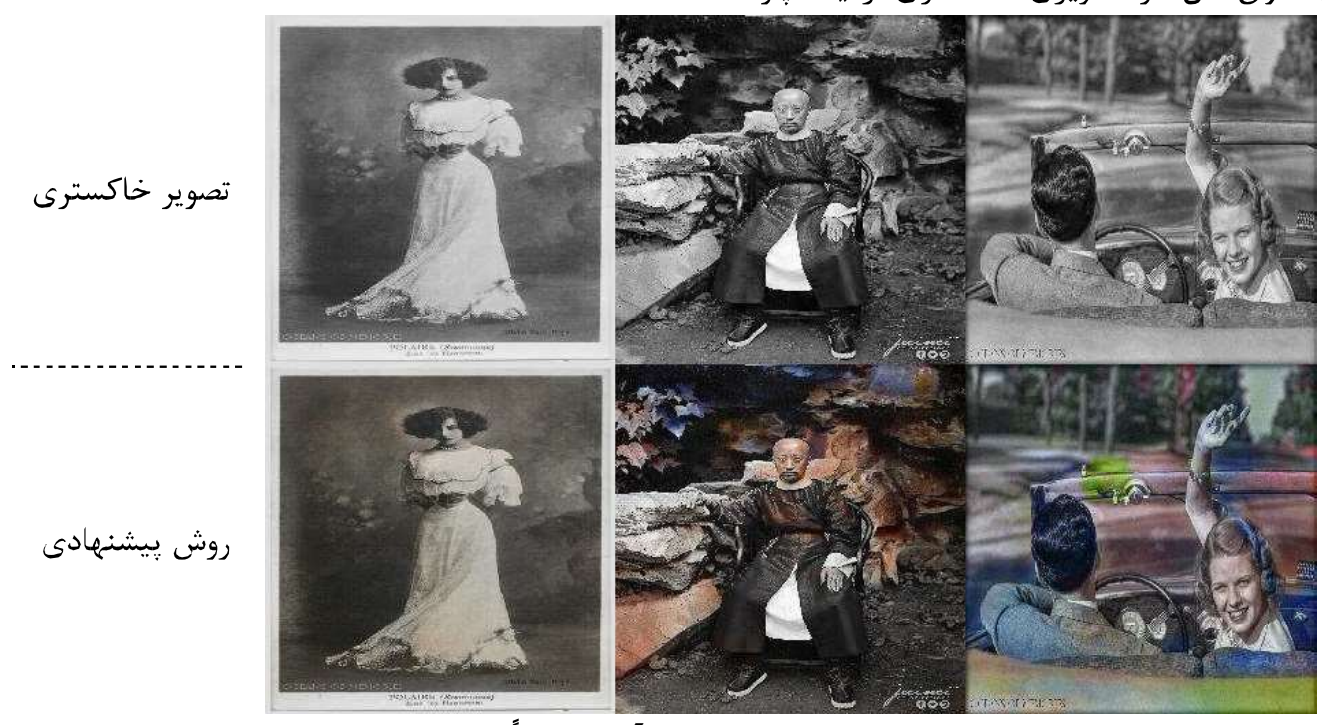

(شكل-1)

(Figure-14): Failed colorizations

در رديف نخست شاهد نقاشىهايى هستيم كه با دست كشيده شدهاند. در بسيارى از موارد طرحهاى هنرى بهعمد رنتَآميزى نمى شوند تا ساختار آن واقعى تر به نظر برسد؛ جِون رنتَآميزى آنها ممكن است از رئاليسمى موجود در طرح

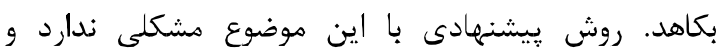
رنتَآميزى بسيار زندهاى براى اين تصاوير ارائه مىدهد تاني

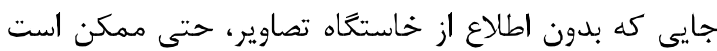
آنها را با تصاويرى واقعى اشتباه كرفت. در رديف سوم به يايين تصاويرى با تنوع بيشتر بررسى شدهاند. در ستون نخست تصوير يك وبكاميك به نمايش درآمده است.
براى بررسى انعطاف نسبت به تصاوير غيرانسانى از

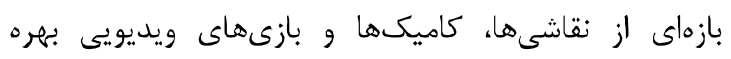
كرفتيهم. در حوزه بازىهاى ويدئويى بسيارى از نويسهها

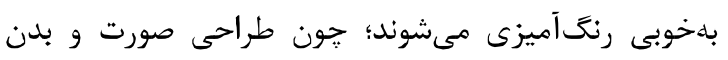
بيشتر آنها همانند انسانهاى واقعى است؛ ولى دئ در حوزئ هون تصاوير هنرى اين هارمونى وجود ندارد كه باعث هىشود،

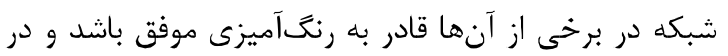
برخى ديكر خروجىهاى نهجندان مناسبى بدهد. در شكل

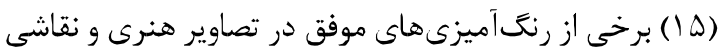
نشان داده شدهاند. 
است كه از لحاظ كيفى با آنجه نقاش ساعتها براى آن زمان

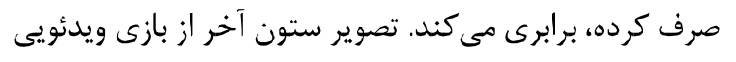
Limbo

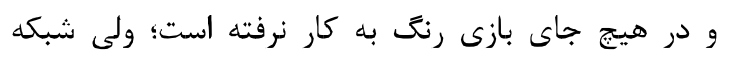

$$
\text { توانسته تصوير را، هرجند بهشكل محدود، رنكَآميزى كند. }
$$

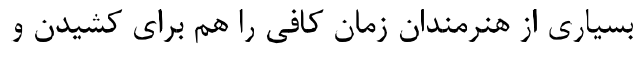

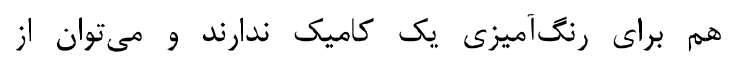

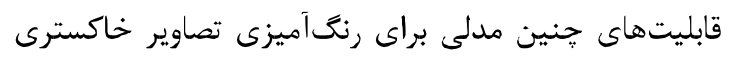

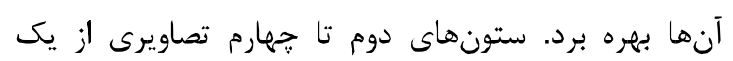

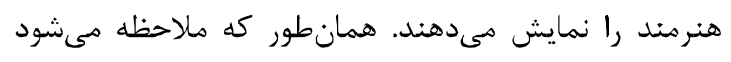
شبكه رنتخآميزى جديدى را براى هر سه تصوير ارئه مائه داده

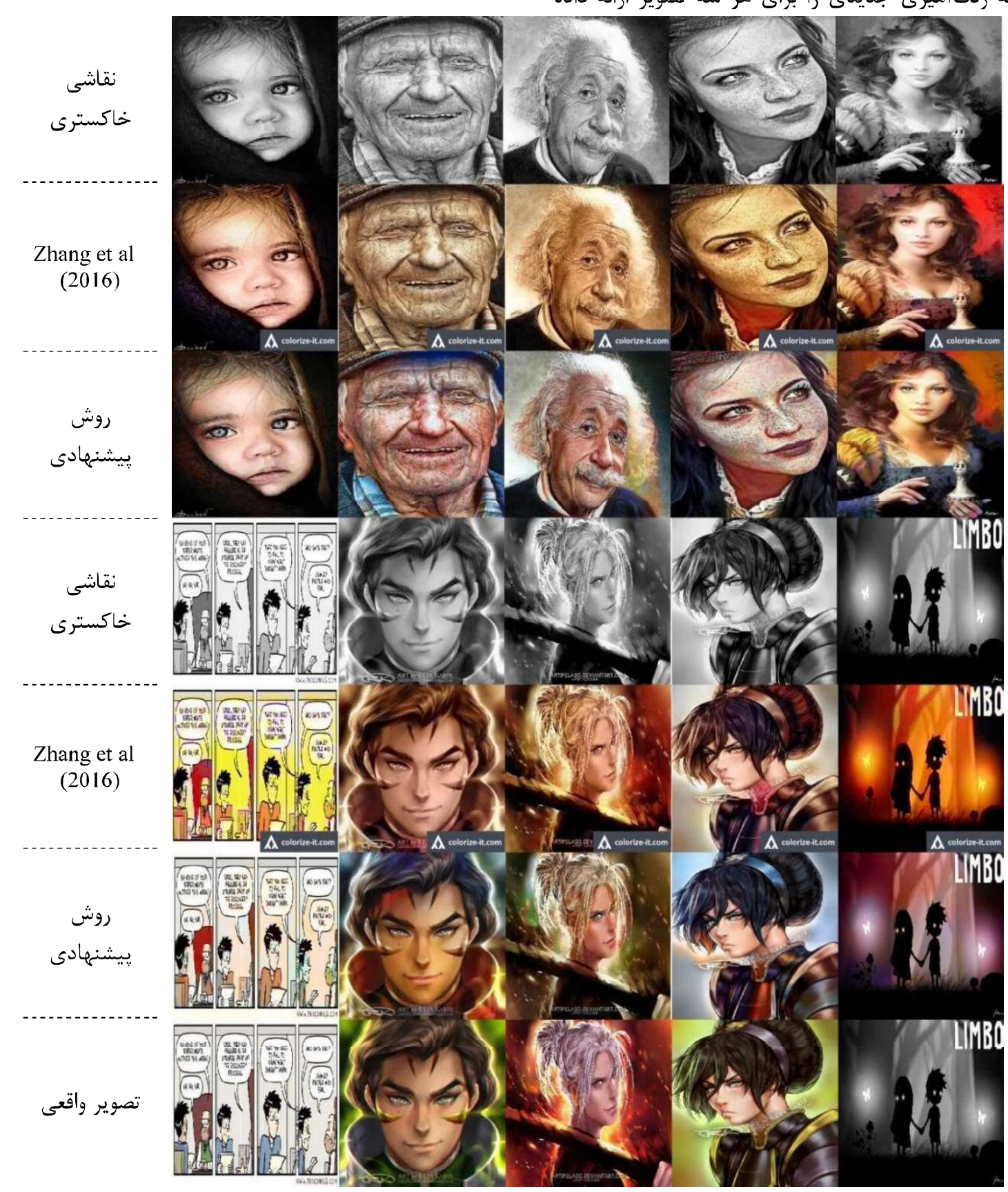

(شكل - (1) : رنكَآميزى تصاوير هنرى

(Figure-15): Colorizing artistic images

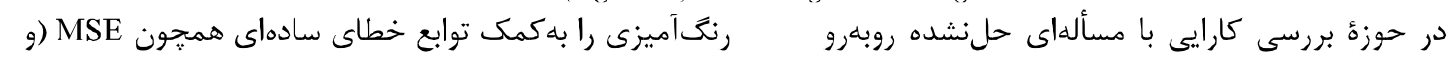

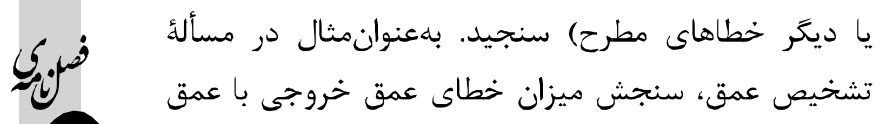

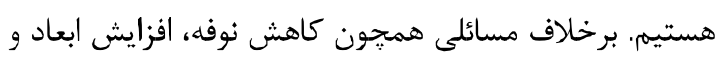
يا تشخيص عمق در تصاوير، نمىتوان كارايى يك مسئلئ

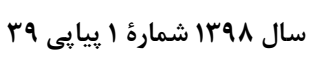


معنايى از دحتواى درون تصوير است، سامانه بهخوبى عمل

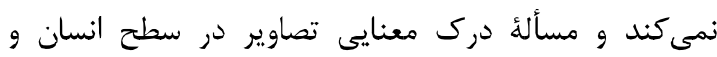

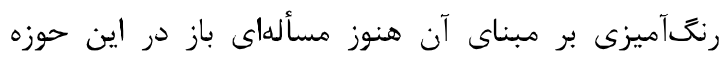

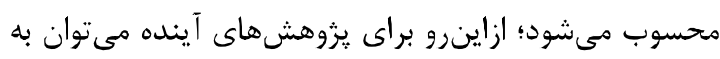

$$
\text { موارد زير اشاره كرد: }
$$

بخش اعظمى از عملكرد شبكه تحت تأثير زمان و ودي

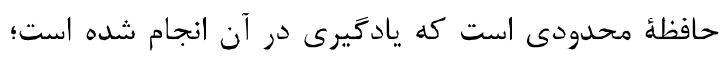

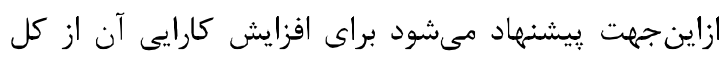

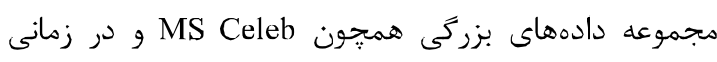

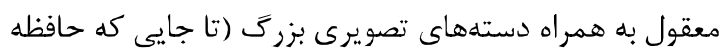

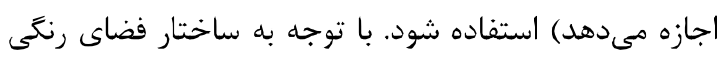

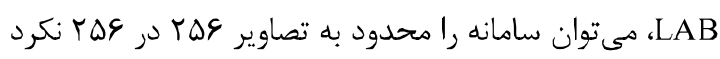

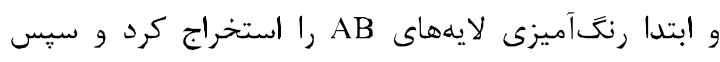

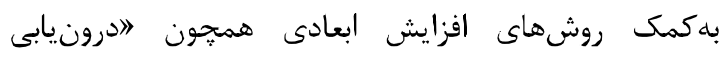

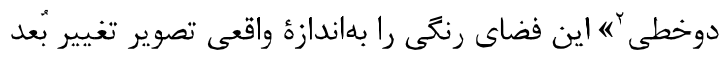

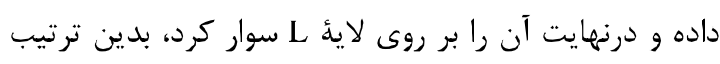

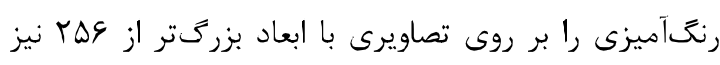

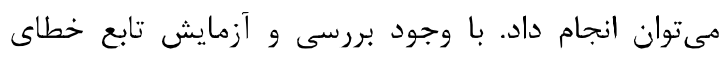
ير Wasserstein

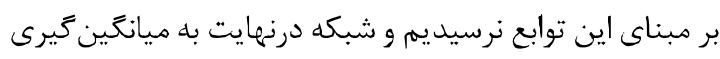

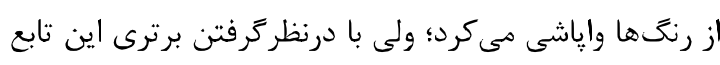
خطا نسبت به توابع خطاى مبتنى بر ديورزانس - Kullback Leibler

$$
\text { بيشترى در اين حوزه بايد انجام شود. }
$$

\section{8- References}

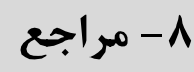

[1] J. J. Lloyd, "The Complexity of Recolouring Photos," 2017. [Online]. Available: https-

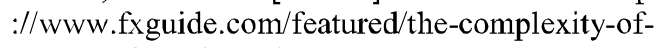
re-colouring-photos/.

[2] "r/colorizationrequests." [Online]. Available: https://www.reddit.com/r/colorizationrequests.

[3] P. Whitt, Pro Photo Colorizing with GIMP. Apress, 2016.

[4] S. Koo, "Automatic Colorization with Deep Convolutional Generative Adversarial Networks," 2016. [Online]. Available: http://cs231n.stanford.edu/reports2016/224_Report.pdf.

[5] Aleju, "Aleju Torch Colorizer," 2016. [Online]. Available: https://github.com/alcju/colorizer.

[6] R. Zhang, P. Isola, and A. A. Efros, "Colorful Image Colorization," Eccv, pp. 1-25, 2016.

[7] R. Dahl, “Automatic Colorization,” 2016.

${ }^{2}$ Bilincar Interpolation
واقعى بهتنهايى و بهكمى MSE قابلمحاسبه است؛ جون خروجى هاى مورد انتظارمان در جنين مسائلى فقط يك تصوير

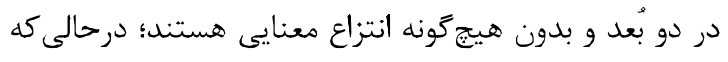

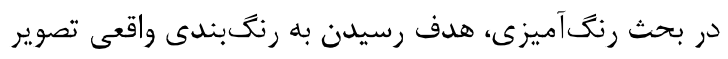

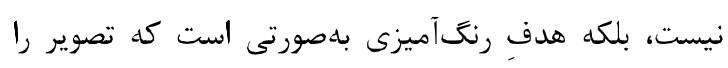

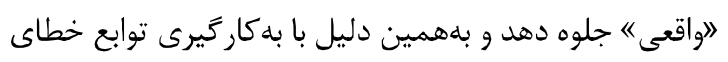

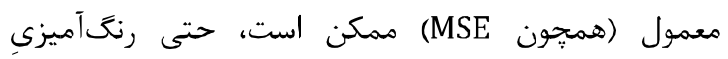

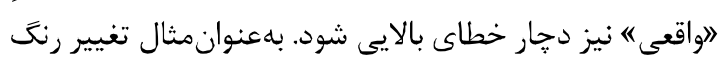

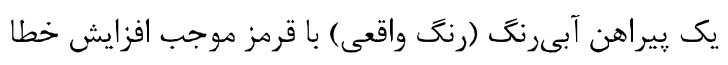

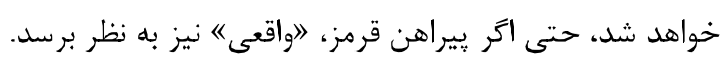

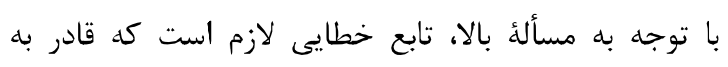

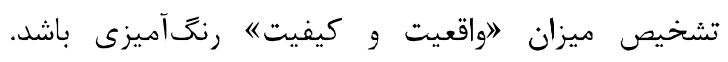

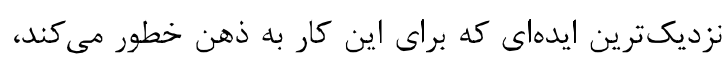

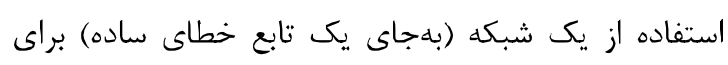

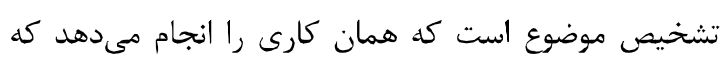
شبكة تمايزى ريشنهادى انجام مى دهد.

\section{- ن}

در اين مقاله سامانهاى هوشمند براى رنغىآميزى تصاوير

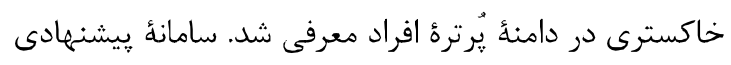

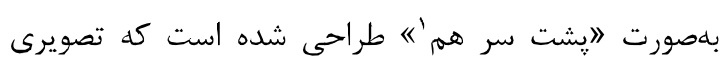

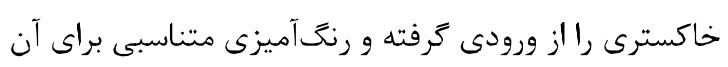

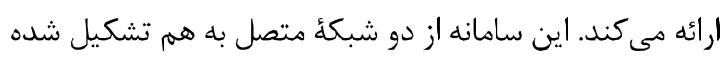

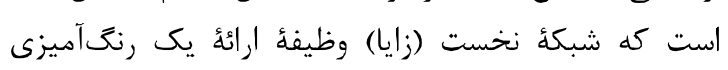

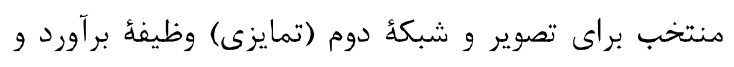

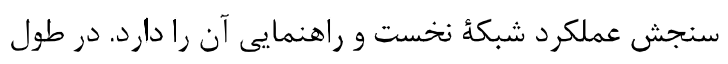

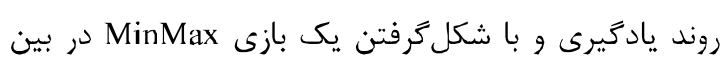

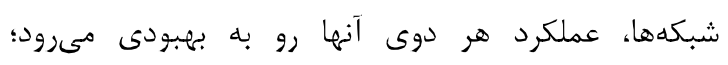

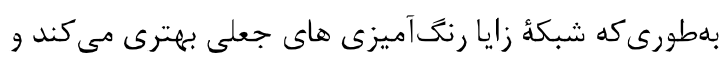

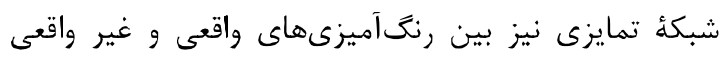

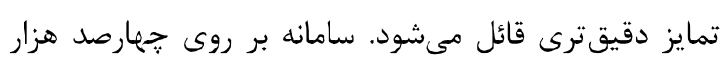

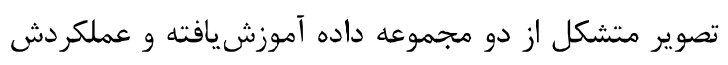

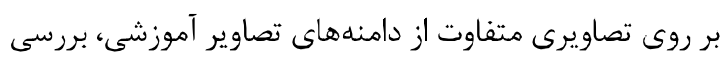

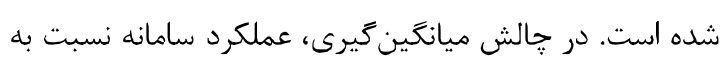

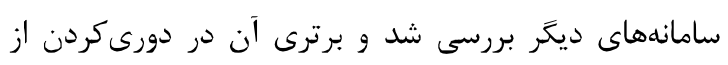

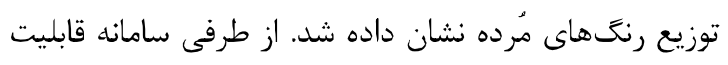

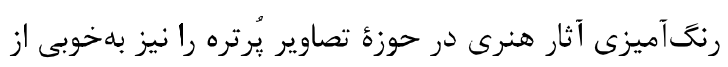

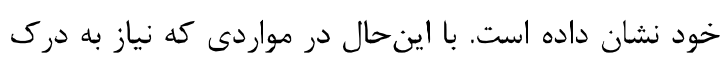

${ }^{1}$ End to End 
[22] K. Simonyan and A. Zisserman, "Very deep convolutional networks for large-scale image recognition," Iclr, vol. 96, no. 2, pp. 1-14, 2015.

[23] K. He, X. Zhang, S. Ren, and J. Sun, "Deep Residual Learning for Image Recognition," Arxiv.Org, vol. 7, no. 3, pp. 171-180, 2015.

[24] S. Iizuka, Edgar Simo-Serra, and H. Ishikawa, "Let there be Color!: Joint End-to-end Learning of Global and Local Image Priors for Automatic Image Colorization with Simultancous Classification," Siggraph '16, vol. 35, no. 4, pp. 111, 2016.

[25] A. Krizhevsky, Ii. Sulskever, and G. E. Hinton, "ImageNet Classification with Deep Convolutional Neural Networks," in Nips, 2012, pp. 1-9.

[26] A. Odena, V. Dumoulin, and C. Olah, "Deconvolution and Checkerboard Artifacts," Drill, pp. 1-14, 2016.

[27] Z. Liu, P. Luo, X. Wang, and X. Tang, "Deep learning face attributes in the wild," Proc. IEEE Int. Conf. Comput. Vis., vol. 11-18-Dece, pp. 3730-3738, 2016.

[28] Y. Guo, L. Zhang, Y. Hu, X. He, and J. Gao, "MSCeleb-1M : Challenge of Recognizing One Million Celebrities in the Real World," Eur. Conf. Comput. Vis., pp. 87-102, 2016.

[29] M. D. Zciler, "ADADELTA: An Adaptive Learning Rate Method,” arXiv, p. 6, 2012.

[30] D. Kingma and J. Ba, "Adam: A Method for Stochastic Optimization," Int. Conf. Learn. Represent., 2014.
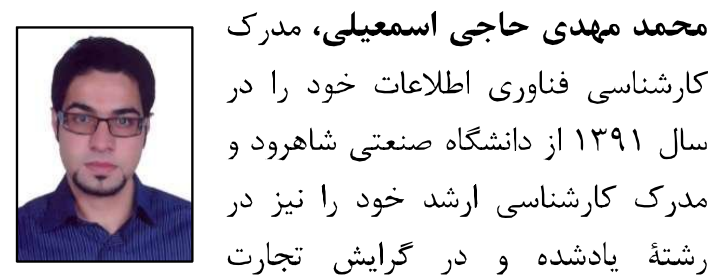

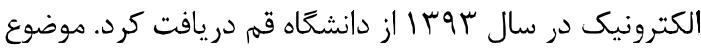

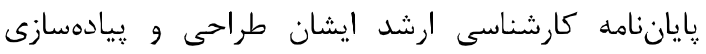

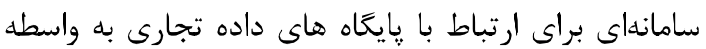
زبان طبيعى بوده است. وى همماكنون دانشجوى مقطع دكترا در همان رشته و در دانشكاه تربيت مدرس است. زمينههاى

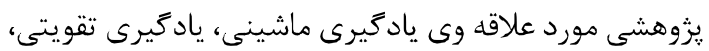
يردازش تصوير و يردازش زبان طبيعى است. نشانى رايانه ايشان عبارت است ازئ

MohammadHaji@Modares.ac.ir
[Online]. Available: http://tinyclouds.org/colorize/.

[8] I. J. Goodfellow, J. Pouget-Abadie, M. Mirza, B. Xu, D. Warde-Farley, S. Ozair, A. Courville, and Y. Bengio, "Generative Adversarial Networks," Jun. 2014.

[9] A. Radford, L. Metz, and S. Chintala, "Unsupervised Representation Learning with Deep Convolutional Generative Adversarial Networks," arXiv, pp. 1-15, 2015

[10] S. Reed, Z. Akata, X. Yan, L. Logeswaran, B. Schiele, and H. Lee, "Generative Adversarial Text to Image Synthesis,” Icml, pp. 1060-1069, 2016.

[11] M. Arjovsky, S. Chintala, and L. Bottou, "Wasserstein GAN," Jan. 2017.

[12] M. Mirza and S. Osindero, "Conditional Generative Adversarial Nets," CoRR, pp. 1-7, 2014.

[13] A. Levin, D. Lischinski, and Y. Weiss, "Colorization using optimization," ACM Trans. Graph., vol. 23, no. 3, p. 689, 2004.

[14] Y.-C. Huang, Y.-S. Tung, J.-C. Chen, S.-W. Wang, and J.-L. Wu, "An adaptive edge detection based colorization algorithm and its applications," Proc. 13th Annu. ACM Int. Conf. Multimed. Multimed. '05, no. January, p. 351, 2005.

[15] L. Yatziv and G. Sapiro, "Fast image and video colorization using chrominance blending," IEEE Trans. Image Process., vol. 15, no. 5, pp. 11201129, 2006.

[16] T. Welsh, M. Ashikhmin, and K. Mueller, "Transferring color to greyscale images," $A C M$ Trans. Graph., vol. 21, no. 3, pp. 277-280, 2002.

[17] R. Gupta, A. Chia, and D. Rajan, "Image colorization using similar images," Proc. 20th ..., pp. 369-378, 2012.

[18] Z. Cheng, Q. Yang, and B. Sheng, "Deep colorization," Proc. IEEE Int. Conf. Comput. Vis., vol. 11-18-Dece, pp. 415-423, 2016.

[19] A. Deshpande, J. Rock, and D. Forsyth, "Learning large-scalc automatic image colorization," Proc. IEEE Int. Conf. Comput. Vis., vol. 11-18-Dece, pp. 567-575, 2016.

[20] G. Charpiat, M. Hofmann, and B. Schölkopf, "Automatic image colorization via multimodal predictions," Lect. Notes Comput. Sci. (including Subser. Lect. Notes Artif. Intell. Lect. Notes Bioinformatics), vol. 5304 LNCS, no. PART 3, pp. 126-139, 2008.

[21] O. Russakovsky, J. Deng, H. Su, J. Krause, S. Satheesh, S. Ma, Z. Huang, A. Karpathy, A. Khosla, M. Bernstein, A. C. Berg, and L. Fei-Fei, "ImageNet Large Scale Visual Recognition Challenge," Int. J. Comput. Vis., vol. 115, no. 3, pp. 211-252, 2015. 


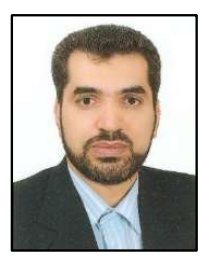

غلامعلى منتظر، مدرى كارشناسى

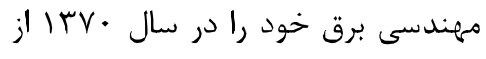

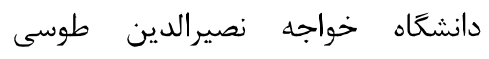
دريافت كرد. وى مدارك كارشناسى ارشد و دكتراى خود را نيز در رشتهٔ ياد

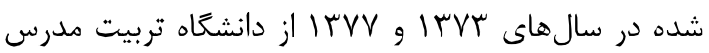

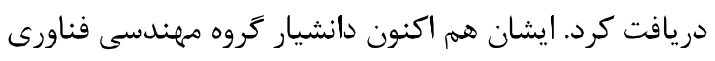

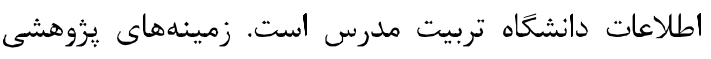

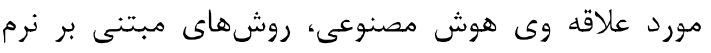
رايانش از جمله نظريه فازى و يادكيرى ماشينى مصنى، يادَّيرى

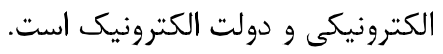
Montazer@Modares.ac.ir نشانى رايانٔ ايشان عبارت است ازي 